\title{
Las Cuevas de Bencomo (La Orotava, Tenerife). De la historiografía al dato arqueológico
}

\author{
The Caves of Bencomo (La Orotava, Tenerife): \\ From Historiography to Archaeological Data
}

\author{
Efrain Marrero Salas* \\ Universidad de La Laguna \\ https:// orcid.org/0000-0003-2547-0095 \\ emarreros85@gmail.com \\ Juan Carlos García Ávila \\ Prored Soc. Coop. \\ https:/ / orcid.org/0000-0003-4826-2504 \\ proredsc@gmail.com \\ Ithaisa Abreu Hernández \\ Prored Soc. Coop. \\ https://orcid.org/0000-0003-4606-5312 \\ proredsc@gmail.com
}

Hacomar Ruiz González

Universidad de La Laguna

https://orcid.org/0000-0001-7372-8754

haruizgon@gmail.com

\author{
Santiago Sossa Ríos \\ Universitat Rovira i Virgili \\ https://orcid.org/0000-0002-0379-0779 \\ santiago.sossa@estudiants.urv.cat \\ Sandra Cancel \\ Servicios Integrales de Patrimonio Histórico \\ https:// orcid.org/0000-0001-8860-4420 \\ arqueometra@arqueometra.es
}

Recibido: 17/06/2020 Revisado: 25/06/2020; Aceptado: 22/10/2020

\begin{abstract}
Resumen
Las Cuevas de Bencomo son uno de los espacios más significativos de la arqueología de Tenerife, ligado especialmente al carácter emblemático por su identificación tradicional con el Mencey de Taoro. No obstante, este espacio no había sido fruto de una excavación sistemática que arrojara luz sobre cuál sería su cronología y su posible funcionalidad, entroncada en ocasiones con el problemático concepto de auchón. El presente artículo plasma los resultados obtenidos de las intervenciones arqueológicas, en las que se procedió a la limpieza de dichas cuevas reutilizadas hasta la actualidad como rediles, y a su excavación y registro pormenorizado.
\end{abstract}

Palabras claves: Tenerife, Bencomo, Guanches, Auchón, Cuevas horadadas.

*Autor de correspondencia / Corresponding author.

Copyright: @ 2021 ULPGC. Este es un artículo de acceso abierto distribuido bajo los términos de la licencia Creative Commons Atribución-NoComercial-SinDerivar (by-nc-nd) Spain 3.0. 


\begin{abstract}
The Bencomo Caves are one of the most significant spaces in the archaeology of Tenerife, especially linked to the emblematic character of the traditional identification with the Mencey de Taoro. However, this space had not been the result of a systematic excavation that would shed light on what would be its chronology and possible functionality, sometimes linked to the problematic concept of auchón. The present article shows the results obtained from the archaeological interventions, in which the caves were cleaned and reused as sheepfolds, and their excavation and detailed recording was carried out.
\end{abstract}

Key words: Tenerife, Bencomo, Guanches, Auchón, Drilled caves.

\title{
1. INTRODUCCIÓN
}

El BIC de las Cuevas de Bencomo está conformado por un caboco ubicado en el Barranco del Pino. Se halla a 356 msnm en el par de coordenadas X: 352467 e Y: 3143245 , con un amplio dominio visual hacia el oeste. El conjunto de cuevas, erosionadas de manera natural y de origen basáltico, está formado por dos oquedades comunicadas entre sí por un pequeño paso, siendo su acceso principal a través de una cornisa aterrazada que conectaría con la boca de dichas cuevas. Inicialmente estaban colmatadas de excrementos de ovicápridos y otros tipos de residuos sólidos y orgánicos, haciendo imposible su tránsito en el interior.

El objetivo inicial de la intervención arqueológica realizada en 2017 era tratar de determinar si las cavidades albergaban aún potencialidad arqueológica. Si fuese así se podría comprobar, a partir de los estudios de los suelos conservados, la correspondencia con las cuevas que recoge la historiografía sobre el lugar y por consiguiente verificar su localización y funcionalidad que desde el siglo XVIII se ha designado como la residencia-auchón del Rey de Taoro. La datación de los suelos conservados así como el análisis de los vestigios arqueológicos servirían para definir el tipo de actividades desarrolladas en las cuevas y, comprobar si efectivamente se trataba de espacios entroncados con un tipo de yacimiento poco estudiado como pueden ser los auchones, de gran significado para la sociedad guanche durante el siglo xv.

\subsection{Contexto geológico}

Las Cuevas de Bencomo se sitúan en la ladera oriental del Valle de La Orotava, en una zona de fuerte pendiente de la cuesta de La Florida. Están ubicadas en una posición intermedia entre el canal Fuente Nueva y el mirador de Humboldt. Forman parte de una colada volcánica cuyo eje mayor se orienta de sureste a noroeste. Están erosionadas por el lateral oeste, donde se abren tres oquedades unidas con vistas hacia el valle (Figura 1), las dos primeras conectadas por un pasadizo de 2,5m de longitud. La tercera oquedad es una prolongación de la erosión de la colada, considerada una tercera cavidad por encontrarse a una 
cota superior y presentar un área superficial de menor tamaño.

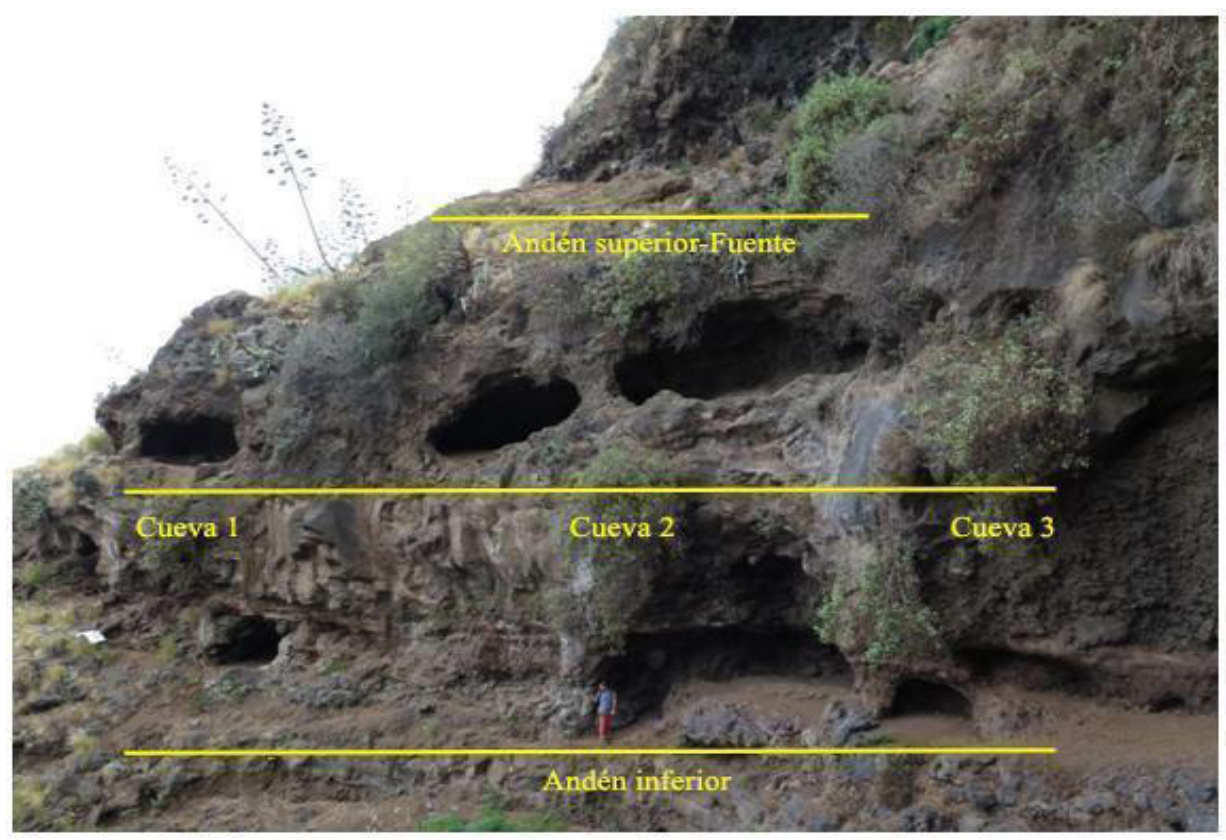

Figura 1. Esquema del conjunto de cuevas en la ladera de Tamaide. Fotografía: Prored Soc. Coop., 28 de agosto del 2017.

La cueva que se localiza más al norte tiene la función de entrada, puesto que es la única accesible a pie desde el andén intermedio de la ladera (cueva 1). Antes de llegar a ella se localiza un espacio que actúa de antesala abierta hacia el caboco del Barranco de El Pino. La erosión de la ladera ha formado tres pisos o andenes, ubicándose las cuevas de mayor entidad y profundidad en el segundo. Las dimensiones de la cueva 1 son $5 \mathrm{~m}$ de longitud, desde su paso hasta su hueco de acceso, 2,20m de altura y 3,40m de profundidad. La boca concretamente mide unos $2,80 \mathrm{~m}$ de ancho por unos $3 \mathrm{~m}$ de longitud. La segunda cavidad tiene dos aperturas al barranco, divididas por una columna basáltica, siendo de mayores dimensiones que la primera oquedad, unos 10,25m de largo, y 3,60m de ancho desde la apertura central hasta la pared, y 3,40m de altura. Por último, tras la limpieza de la totalidad del estiércol de las cuevas definimos un tercer espacio que formaría parte de la extensión de la cavidad 2 y que corresponde con una oquedad abierta igualmente hacia el caboco, cuyo suelo está elevado en forma de rampa.

En el andén inferior se documentan dos cavidades más. La primera de ellas presenta acondicionamiento de su entrada con cierre de mampostería (cemento y ladrillos), si bien su superficie interior no es muy espaciosa y contiene restos de 
estiércol. La segunda, de mayores dimensiones que la primera, no presenta un acondicionamiento reciente, aunque es cierto que también su suelo está cubierto por un depósito de estiércol. Por toda el área del andén inferior y zonas más próximas al caboco se localizan en superficie dientes de suidos y fragmentos de cerámica popular y de importación.

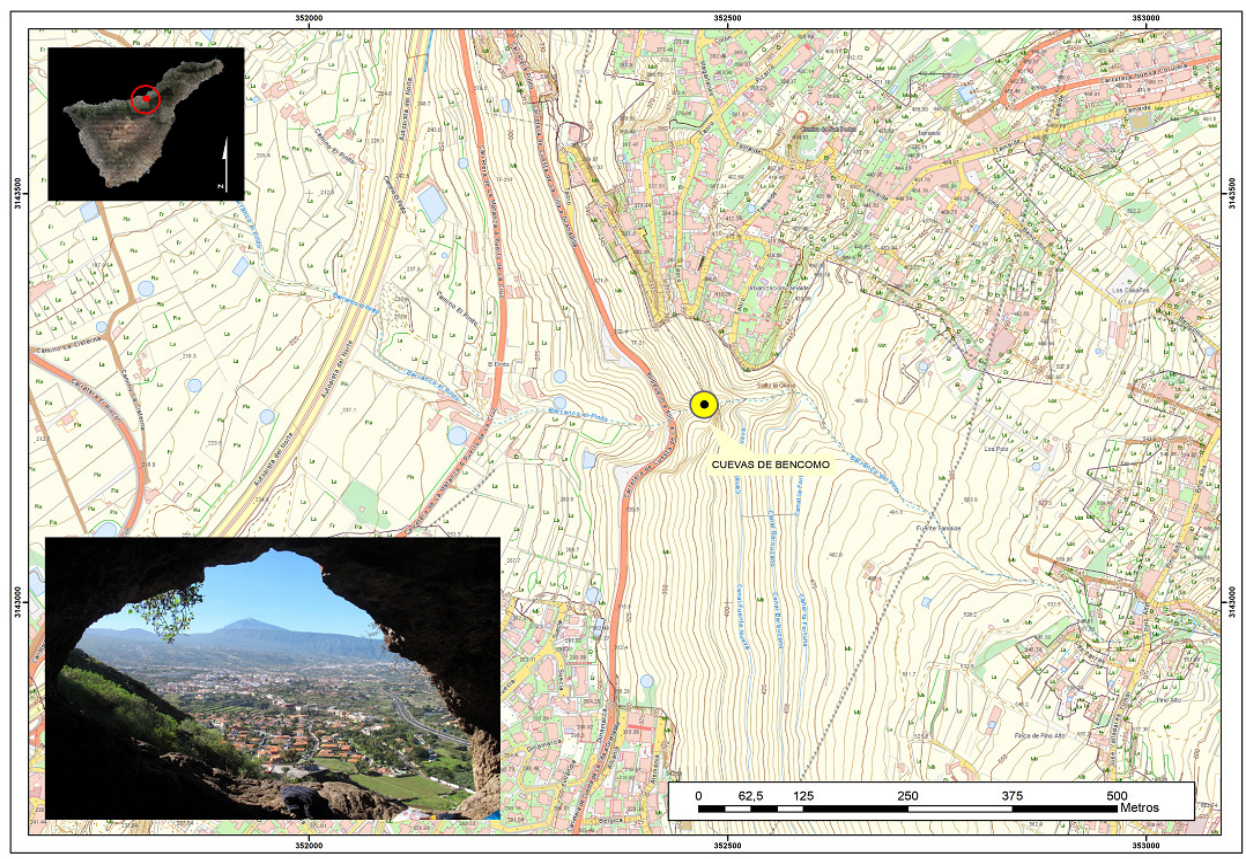

Figura 2. Plano de localización de las Cuevas de Bencomo.

En lo que respecta al andén superior, se identifica una fuente natural que en algunos de los documentos históricos la sitúan a unos 50m de las cavidades del Mencey Bencomo, y describen como «una pequeña oquedad con profundidad por la que resuma agua» (SERRA,1978: data 613-14).

Las condiciones en las que se encuentra esta cavidad son similares a las restantes del conjunto, donde el estiércol cubre la superficie y los escombros de antiguos vallados de metal se hallan desperdigados por el entorno. Además, se documenta también restos de añadidos de mampostería reciente, de ladrillo y cemento, que delimitaban el hueco de salida y la canalización de las aguas. A esto hay que añadir la existencia de una canalización adosada y labrada en la toba roja, ubicada en el exterior de la galería natural y que a su vez aprovecharía la captura del agua de escorrentía por la ladera rocosa. 


\section{ANTECEDENTES PATRIMONIALES Y ARQUEOLÓGICOS}

Las Cuevas de Bencomo tienen la consideración de Monumento Histórico desde el 2 de abril de 1986, según consta en el BOCAC, núm. 38, Decreto 49/1986 de 14 de marzo; y catalogadas por la misma ley como zona arqueológica (RI-510008739). Hasta esta publicación y como bien apuntaba el historiador TejERA (2016: 59-60): «no se cuenta con un trabajo para desechar, o en su caso confirmar, el verdadero destino del yacimiento, que seguramente pervivió en la memoria como el lugar verdadero de lo que fuera la vivienda del antiguo Mencey, tradición que explicaría por qué Álvarez Ríxo la consideraría su morada».

En cuanto a las fuentes arqueológicas, solo se dispone de descripciones superficiales del entorno de estas cuevas. Queda constancia que ya en 1944 las cuevas habían sido fruto de un expolio intenso pues, exploradas por Luis Diego Cuscoy, Álvarez Delgado (1947) menciona únicamente la localización de tres amorfos cerámicos. ${ }^{1}$ Es interesante señalar que las dimensiones aportadas por Álvarez Delgado coinciden con las dimensiones aportadas por Álvarez Rixo, si bien el primero menciona que los suelos de estas cuevas pudieron haber sido excavados por parte de los campesinos canarios, dada la costumbre de reutilizar estos suelos como abono para las tierras de cultivo.

Hasta el año 2017 no se había realizado una intervención arqueológica sistemática $\mathrm{y}$, en extensión, en el interior de las cavidades ${ }^{2}$ que apoyase o contradijera la información recabada en las fuentes escritas. La descripción de las cuevas que realiza Eduardo Tarquis en los años 80 del siglo pasado volvía a apuntar la idea ya planteada de que el uso de este espacio como redil para el ganado le había restado potencialidad arqueológica a las mismas.

\section{METODOLOGÍA}

Uno de los principales objetivos de la intervención era excavar en extensión, con metodología arqueológica actualizada y con registro 3D, aquellas superficies en la que quedase depósito arqueológico. El fin era obtener el máximo de información posible a partir de cualquier superficie que pudiera ser tratada con rigor, de una manera eficiente. Además de realizar un registro geométrico de todas las cavidades. ${ }^{3}$

\footnotetext{
1 Informes y Memorias, núm. 14: «El piso de la cueva ha debido de ser limpiado en otras ocasiones pues no se hallaron fragmentos de cerámica ni utensilios, sólo en unas grietas se hallaron tres cortos fragmentos de cerámica de estructura indudablemente indígena. Informaciones, que no han podido ser comprobadas, aseguran que se recogieron de allí elementos aborígenes hace años por turistas que las visitaron» (Álvarez Delgado y Diego Cuscoy, 1947: 30-31).

2 Luis Diego Cuscoy realizó catas en los alrededores de las cuevas, en la misma fuente del Pino o Tamaide o andén superior de la ladera, donde encontró fragmentos de cerámica y obsidiana. Sin embargo, no se conoce el paradero de estos objetos.

3 Para el registro tridimensional de las paredes y techos de las cavidades se contó con el trabajo de Sandra Cancel, representante de la empresa Arqueometra S. L.
} 


\subsection{Geoarqueología: interpretando los estratos}

En los trabajos de arqueología de campo se emplean dos estrategias de actuación bien diferenciadas: tallas o levantamientos. Uno es el sistema de excavación determinado a través de proporciones regulares de decapado del sedimento, es decir, de capas de un grosor previamente establecido; y el otro sistema es el microtopográfico, que respeta los contactos de las diferentes unidades sedimentarias, las leyes de la estratigrafía y su morfología de génesis (VALLVERDú, 2002). El espesor, la pendiente y los levantamientos de cada unidad arqueosedimentaria son características variables y su detección depende de los apoyos de todos los elementos materiales que las integran, ya sean antrópicos o no (piedras, derrumbes, piezas de fauna, cerámica, etc.). Con respecto a esta intervención, se llevó a cabo la excavación del depósito arqueosedimentario aplicando el proceso de levantamientos microestratigráficos.

Uno de los propósitos fundamentales en la excavación arqueológica es reconocer e identificar los posibles suelos de ocupación, las características estratigráficas de cada uno de los levantamientos realizados y determinar las facies arqueosedimentarias (áreas de especial naturaleza y con una génesis determinada), como puede ser la huella de un área de combustión u otra actividad antrópica (MARRERO et al., 2011; 2016). La aplicación de este método facilitó el reconocimiento de las condiciones de formación del relleno arqueológico, además de permitirnos la identificación de los diferentes procesos postdeposicionales que hayan afectado al yacimiento.

El cribado del sedimento, así como la recogida y selección de muestras sedimentarias permitirán el estudio de los restos carpológicos que puedan ser recuperados en el contenido de tierra de cada cuadrícula excavada, proporcionando valiosa información sobre las actividades realizadas en los suelos de la cavidad 2. Estos análisis aportarán datos directos sobre la funcionalidad del yacimiento y la comprensión de la actividad agrícola y recolectora por parte de los ocupantes de las cuevas de Bencomo, y de la isla de Tenerife en general (Morales et al., 2017). Los estudios del material antracológico también revelarán los usos de estos espacios. Los frecuentes hallazgos en forma de carbones, sobre todo, pero también en madera de los yacimientos en Canarias a partir de procesos de flotación de sedimentos, se convierte en otro procedimiento esencial a la hora de abordar una investigación multidisciplinar (VIDAL et al., 2020).

\subsection{Registro arqueológico: la fotogrametría}

La fotogrametría es una técnica para determinar las propiedades geométricas de los objetos y de las superficies a partir de imágenes fotográficas. De acuerdo con la necesidad de un modo de registro que se adapte a una realidad 3D en constante cambio, a causa de la excavación secuencial de las superficies de un yacimiento (y por tanto de la destrucción del objeto de análisis), es obligado documentar en cada momento las superficies estratigráficas. El control de los 
datos dimensionales de las imágenes permite que los objetos mostrados en las reconstrucciones tridimensionales puedan ser medidos y representados a escala de la realidad. Las aplicaciones fotogramétricas utilizadas por nosotros difieren sensiblemente de la fotogrametría tradicional, a pesar de que el resultado sea obtener, en ambos casos, un modelo en 3D (ÁlAMO y CANCEL, 2019). En el caso que nos ocupa, el registro por medio de la fotogrametría basada en SFM (ToMÁs et al., 2016), permite obtener registros muy precisos y de alta calidad de todo el proceso de la excavación arqueológica. De la misma manera ocurre con el registro de las paredes y suelos rocosos de las cavidades, a los que también se le ha aplicado esta técnica de registro. Con ello se ha obtenido un modelo tridimensional lo más próximo a la realidad. La información generada, al estar georreferenciada y en un formato compatible, puede ser tratada con un sistema de información geográfica (SIG).

\subsection{Materiales}

En cuanto al tratamiento del material arqueológico que se recuperó de la intervención, se analizó cuantitativamente aquellas naturalezas que nos permitían, de una manera directa desde su recogida en campo, realizar un análisis general con el objetivo de discernir las posibles actividades desarrolladas en los suelos de la cueva. Para ello contamos con los estudios previos sobre los vasos cerámicos guanches de Tenerife, sobre sus tipologías y la capacidad de los recipientes (ARNAY y GoNZÁLEZ, 1984), y la proporción de restos faunísticos según las partes anatómicas que se hallan en las unidades sedimentarias, y que nos informan sobre el procesado y consumo de las especies de la cabaña ganadera en época aborigen (Alberto, 2004).

Uno de los propósitos de esta intervención era obtener alguna datación absoluta que pudiese aportarnos un rango cronológico fiable sobre el uso de las cuevas, especialmente del depósito sedimentario de adscripción aborigen y que correspondería a los suelos de ocupación sin alterar. Las muestras seleccionadas se enviaron al laboratorio de Beta Analytic Inc y las fechas que nos aportaron los resultados son presentadas según el protocolo sugerido por MiLlaRD (2014), usando las convenciones de los trabajos de STUIVER y POLACH (1977). Las fechas calibradas se muestran en rangos de 1 y 2 sigmas respectivamente y calibradas con el software Oxcal (BRONK, 2017), con curva IntCal13 (REIMER et al., 2013).

\section{RESULTADOS: DESARROLLO DE LA INTERVENCIÓN}

\subsection{Cueva 1}

Una de las evidencias más significativas fue la identificación y registro de una serie de canales y cazoletas, presentes en varias superficies del vano de la entrada a la cavidad 1 y en los márgenes de la ventana exterior de la cueva 2. Estos 
orificios podrían tener su origen en la evacuación del agua de lluvia en el primer caso y en la colocación de una mampara de protección en el segundo.
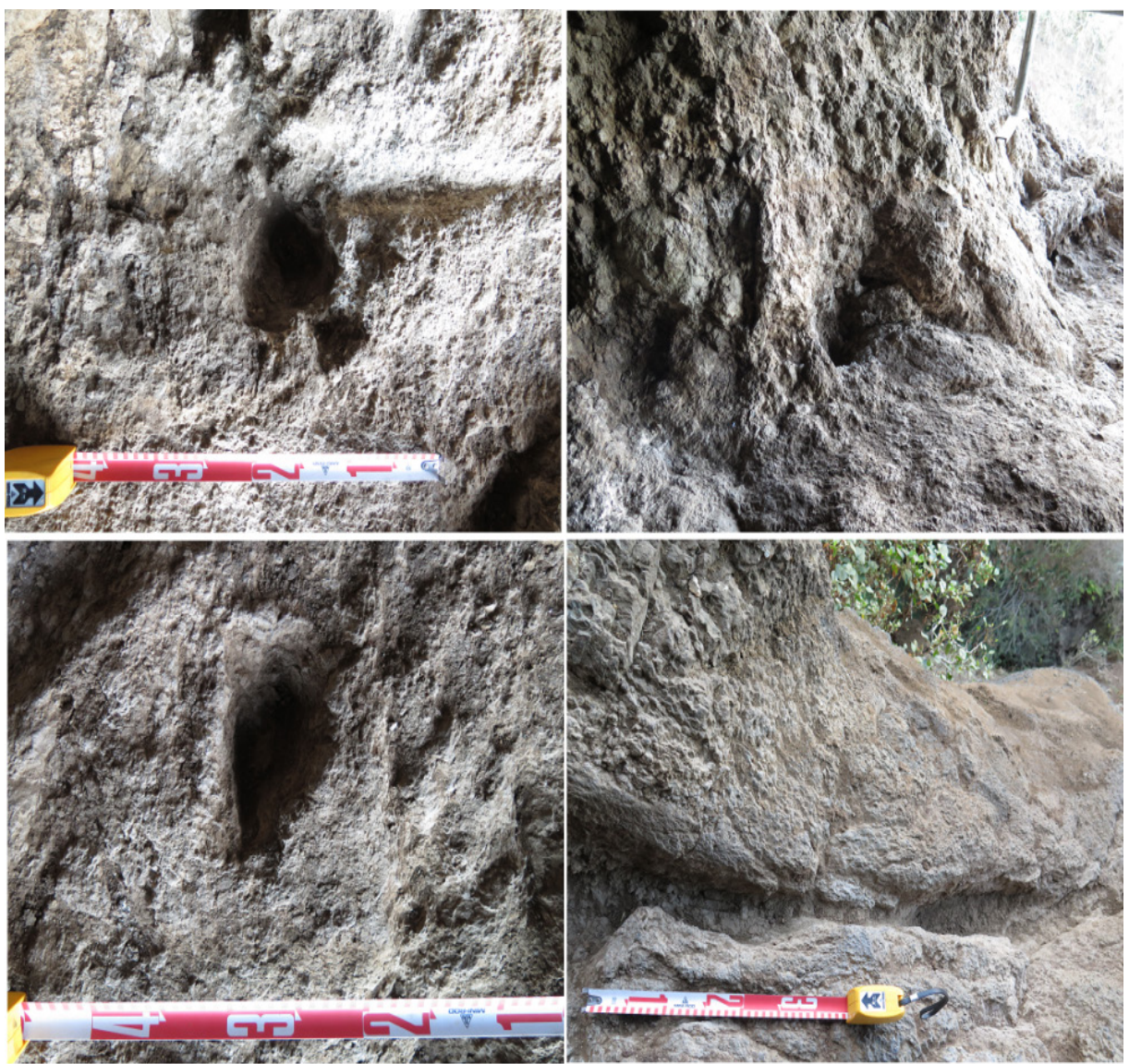

Figura 3. Surcos y canales ubicados en el suelo que da acceso a la cueva 1. Fotografía: Autores.

Tras la extracción del estiércol de toda la cavidad, y de manera específica entre las grietas de la entrada, se localizaron varias ranuras artificiales relacionadas con el acceso a la cueva, ubicadas en los laterales. Se comprobó, además, que en el techo de la entrada existían dos oquedades cuya génesis no corresponde con la meteorización natural de las cuevas. A esto se debe añadir que uno de los laterales de la pared de la antesala se mostraba acondicionado (Figura 4). Se interpreta que dichos trabajos deberían estar relacionados con alguna remodelación de la morfología natural del hueco de acceso para conformar un tipo de cerramiento de estas cuevas. 
Por consiguiente, la aparente disposición y localización en los márgenes del hueco de acceso, tanto en techo como en suelo, indica una intencionalidad clara para disponer y colocar algún soporte de sellado del hueco, como si a modo de puerta, guía y gozne estuviesen destinadas cada una de las ranuras labradas en la roca. Toda la pared de entrada presenta evidencias de acondicionamiento, que le confiere una tendencia cuadrangular, también en los márgenes y suelo del hueco de acceso (Figura 4). Ya en la cueva, hacia el interior, se limpiaron las grietas laterales del suelo donde se hallaron dos superficies cenicientas con abundantes restos de carbón, aunque no se localizaron materiales arqueológicos asociados.
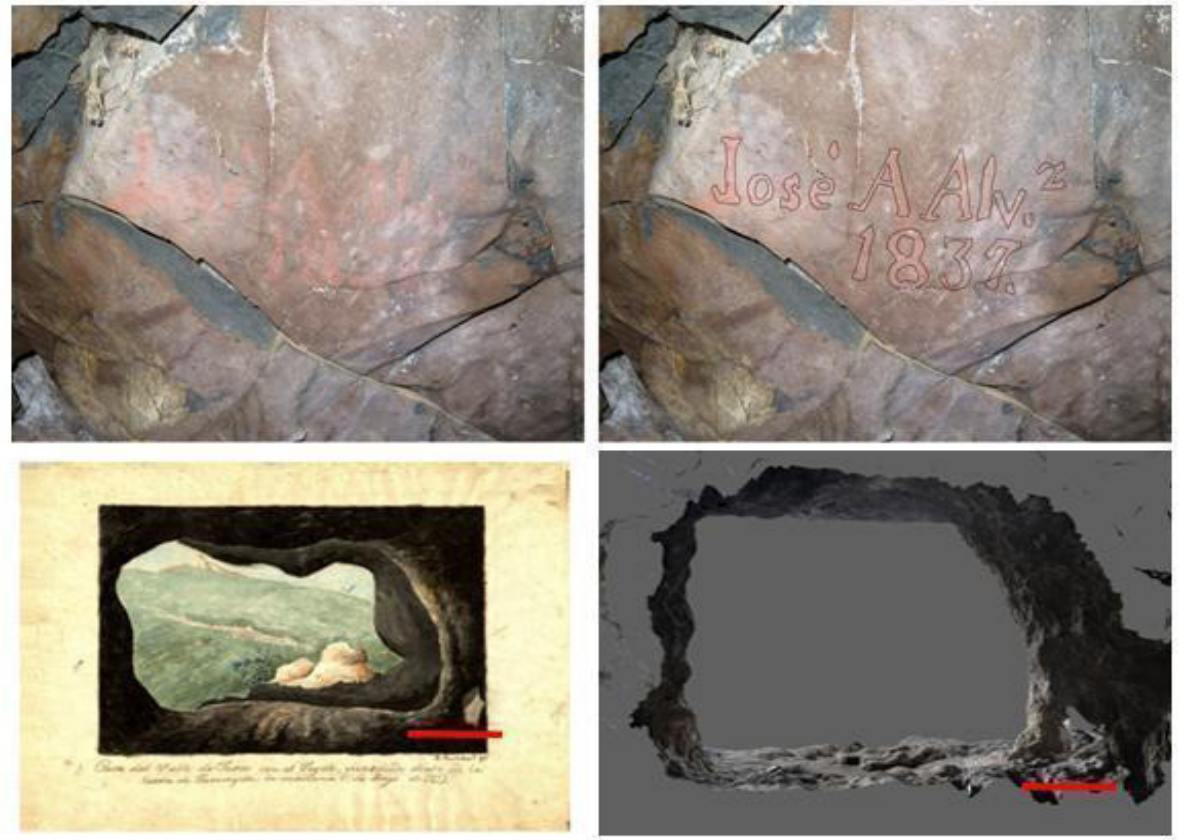

Figura 4. En la parte superior se muestra el grafiti elaborado por José Agustín Álvarez Rixo, en el techo de la cavidad 1. En la parte inferior, representación pictórica de Á. Rixo, y visión 3D desde el interior de la cavidad 1, comprobándose que se trata del mismo hueco de acceso a las cavidades. Fotografías: Autores.

En el interior de la cavidad se produce otro de los hallazgos interesantes de esta cueva 1, que fue localizado en el techo de la misma. Se trata de un grafiti realizado con almagre en el que se puede leer "José A Alv.¹837», lo que parece indicar con toda seguridad que dicha impronta fue realizada por el cronista portuense (Figura 3). ${ }^{4}$ De su visita a las cuevas ya teníamos referencia en la documentación escrita, a pesar de que el propio Álvarez Rixo nos informara de un tipo de marca similar pero de coloración blanca en la que se indicaba la propiedad de la cueva, de la

4 El historiador Daniel García Pulido mencionó este posible grafiti a través del períódico El Día, 16 de marzo de 2009. 
cual no hallamos rastro. Otra evidencia de que esta cueva fue visitada por Álvarez Rixo tiene que ver con la representación pictórica que hace desde el interior de la cavidad 1, con vistas al valle de La Orotava, ya que pudimos observar que tiene las mismas características geomorfológicas en los márgenes del acceso (Figura 3).

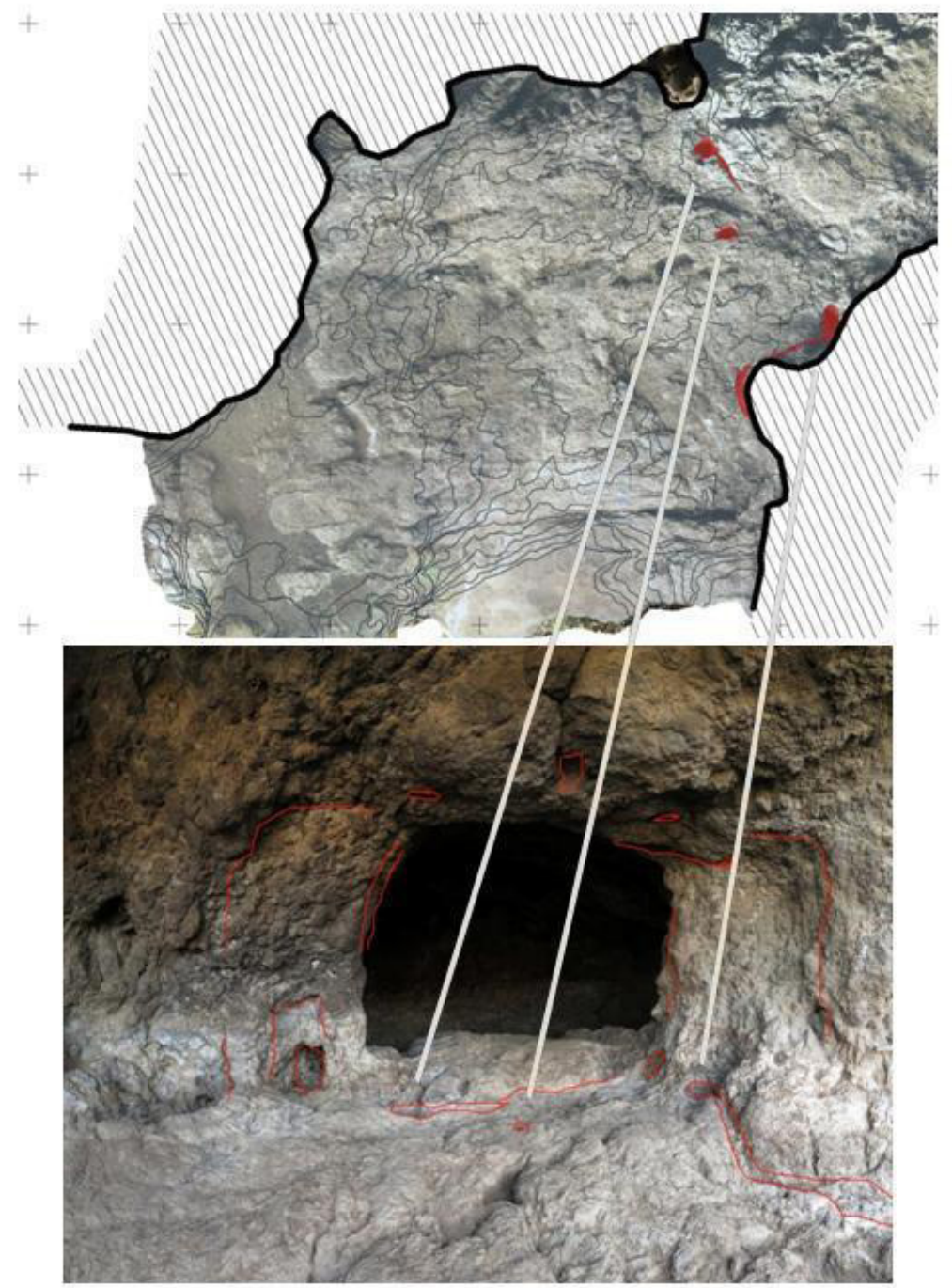

Figura 5. Imagen superior, planimetría del suelo del acceso a la cavidad 1. Imagen inferior, ubicación de cazoletas en la antesala y hueco de acceso. Fotografía: Autores.

La representación de un hueco en el lateral izquierdo del acceso evidencia sin lugar a duda que se trata de la misma cavidad, hueco cuyo contorno exterior se encuentra alterado de manera artificial otorgándole una morfología cuadrangular 
(Figura 5). Lo mismo ocurre con el canal vertical del contorno derecho del hueco de acceso. Sin embargo, la visión del Teide desde esta perspectiva interior de la cavidad 1, tras pasar el umbral del acceso, es una instantánea romántica que quiso plasmar el cronista puesto que esa imagen sólo es perceptible desde la cavidad 2.

\subsection{Cueva 2}

Esta cavidad se localiza a una cota superior que la anterior, unida a ella por un pasadizo natural, inclinado, de 2,5 metros de longitud. El estiércol, en el pasadizo, se apoyaba directamente sobre la roca natural por lo que la limpieza se realizó rápidamente, teniendo el estrato las mismas características que en la cueva 1. La potencia de estiércol en el resto de la cavidad 2 fue sensiblemente inferior a la 1, alcanzando $70 \mathrm{~cm}$ en la parte más profunda y $60 \mathrm{~cm}$ en los laterales.
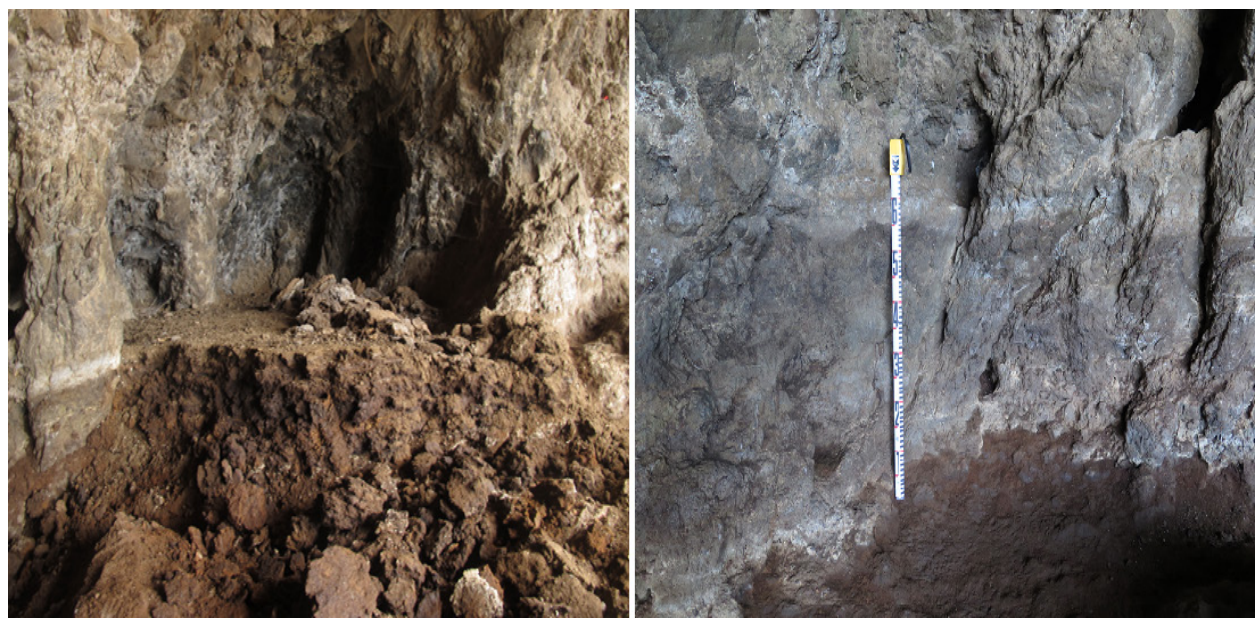

Figura 6. Aspecto que presentaba la cueva 2 durante la excavación de las capas de estiércol y cota de la profundidad que alcanzó en los laterales de la cueva. Fotografías: Autores.

Una vez en el interior de la cueva se localizaron los primeros restos arqueológicos. Se trataba de tres pequeños fragmentos de obsidiana, en la zona central, siendo este hecho fundamental para determinar la cota mínima a la que se debía profundizar. Con la retirada del paquete de estiércol se evidenciaron una serie de marcas y oquedades en las paredes. En la ventana erosiva de la cueva, tanto en el lateral norte como en la columna natural que se ubica al sur, se hallaron unos surcos artificiales que parecían estar relacionados entre ellos. Su disposición hace pensar que servirían de tope para colocar un travesaño y poder así sellar de alguna manera la abertura natural que da al caboco, ventana desde donde se 
puede visualizar el Teide y parte del valle de La Orotava.

\subsection{El depósito sedimentario}

Una vez analizadas las paredes y superficies de los tres espacios geológicos, así como el suelo de la antesala de acceso de la primera cavidad, se realiza la excavación en extensión de los depósitos que se conservan en dos de ellas. Ni la antesala de acceso, ni el final de la formación rocosa en rampa (cueva 3) conservan ningún tipo de sedimentación por lo que se descartan como áreas para la intervención. En total se identifican dos unidades estratigráficas. En lo que respecta a la primera cavidad, el espacio es mucho más reducido y la presencia de sedimentación se concentraba en el centro, abarcando una superficie no mayor de 5x2m de extensión de depósito (Figura 6). Antes de describir la escasa secuencia estratigráfica que aún se conservaba en las cavidades, tras sufrir diferentes etapas de reutilización, extracción y expolio desde el siglo xvI, cabe destacar que el depósito de estiércol de cabra de alguna manera ha conservado la unidad estratigráfica aborigen que hemos identificado. Sin embargo, el estado de conservación sedimentario y el de los vestigios arqueológicos localizados en ella no es óptimo, puesto que están afectados de manera directa por la bioturbación animal, por falta de oxigenación y por la afección de los orines y ácidos procedentes de la descomposición de un depósito orgánico que en la primera cavidad alcanzó el metro y medio de espesor y en la segunda cavidad $70 \mathrm{~cm}$ de alto. No obstante, y a pesar de lo que se creía a partir del trabajo de documentación previo a la intervención, la cueva 2 aún conservaba un depósito estratigráfico correspondiente a suelos de ocupación guanche. Esta realidad sedimentaria, en la cueva de mayores dimensiones, alcanzaba hasta $12 \mathrm{~cm}$ de potencia estratigráfica.

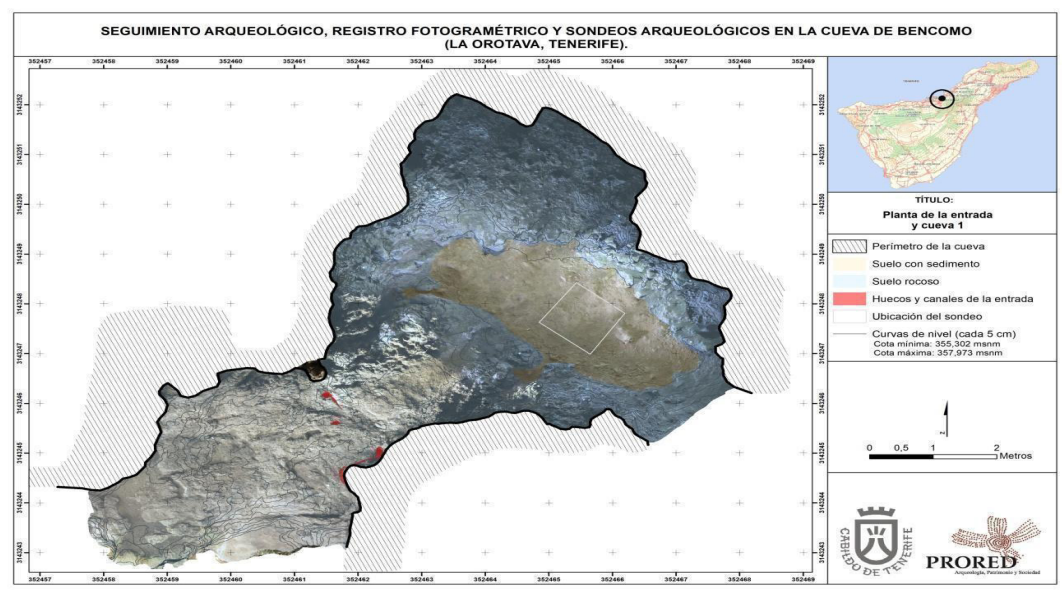

Figura 7. Planimetría de la antesala de acceso y primera cavidad. Ubicación del sondeo realizado. Elaboración propia. 
El techo de este depósito sedimentario está cubierto por la unidad estratigráfica 1 , presente en ambas cavidades, y asociada con la interfacies de contacto entre el relleno de estiércol y la unidad subyacente. Se interpreta como una unidad que no debe tener una formación superior a los 200 años dada a la descripción que hacía Álvarez Rixo en referencia al repunte de algunas rocas ocultas en los suelos de las cuevas. El estrato de UE-2 se identifica exclusivamente en la cueva 2, la que presenta una huella clara de ocupación guanche. Que dicho depósito no se localice en la cueva 1 puede responder a que se retirasen los estratos a lo largo de la historia para el aprovechamiento como fertilizante en el campo, práctica muy común en el siglo XVI, como algunas fuentes históricas documentaron para otras cavidades. En el depósito de la UE-2 se evidenciaron las huellas del impacto de fuegos de adscripción guanche, cuyas facies sedimentarias carbonosas estaban poco estructuradas y con afecciones por procesos postdeposicionales.

La primera de las facies carbonosas por procesos denominada como FC1, se extendía unos $10 \mathrm{~cm}$ hacia el oeste, adosada a la pared de la cavidad, con $2 \mathrm{~cm}$ de potencia. En su base apareció material termoalterado y unas manchas amarillentas, alargadas y bien definidas que parecían corresponder con una facies de cenizas. Estas cubrirían una segunda facies carbonosa (FC2), con unos límites más extensos que la anterior. Cabe señalar que los eventos de combustión están asociados a varios restos de ictiofauna y a un fragmento de cerámica del grupo $\mathrm{III}^{5}$, de morfología y acabado muy tosco. Progresivamente, se fue desarrollando la excavación de los diversos levantamientos que conformaban la UE-2, un total de 9, que se iban restringiendo a las oquedades del suelo irregular de la cavidad y a los márgenes de la superficie, adosada a la pared y al centro del área. Además, en las paredes de este espacio, la propia geomorfología definía dos oquedades sobre elevadas (Figura 8), a modo de hornacinas en la pared. Una de ellas presentaba en su superficie un depósito diferente, caracterizado por un área carbonosa, como si del impacto de una hoguera se tratase. En el hueco del oeste, de similares características que el anterior, la sedimentación era más oscura definida por unos limos ocres con restos de carbón. En algunos de los levantamientos realizados de la UE-2, se documentaron una gran cantidad de $\operatorname{clastos}^{6}$ que fueron interpretados como acumulaciones procedentes del desprendimiento y proceso erosivo del techo y pared de la cavidad.

\footnotetext{
5 Pertenecen a este grupo los grandes vasos u «anforoides» con asas de cinta (ARNAY y GonZÁlez, 1984). 6 Nos referimos al tamaño y morfología de la composición de las litofacies identificadas en la matriz de las unidades estratigráficas, siendo de mayor a menor en su escala los siguientes términos normalizados por la USCS (Unified Soil Clasification System): Bloques $>300 \mathrm{~mm}$, Clastos $75-300 \mathrm{~mm}$, Gravas $4.8-75 \mathrm{~mm}$, Arenas $4.8-0.08 \mathrm{~mm}$ y Limos $<0.08 \mathrm{~mm}$.
} 


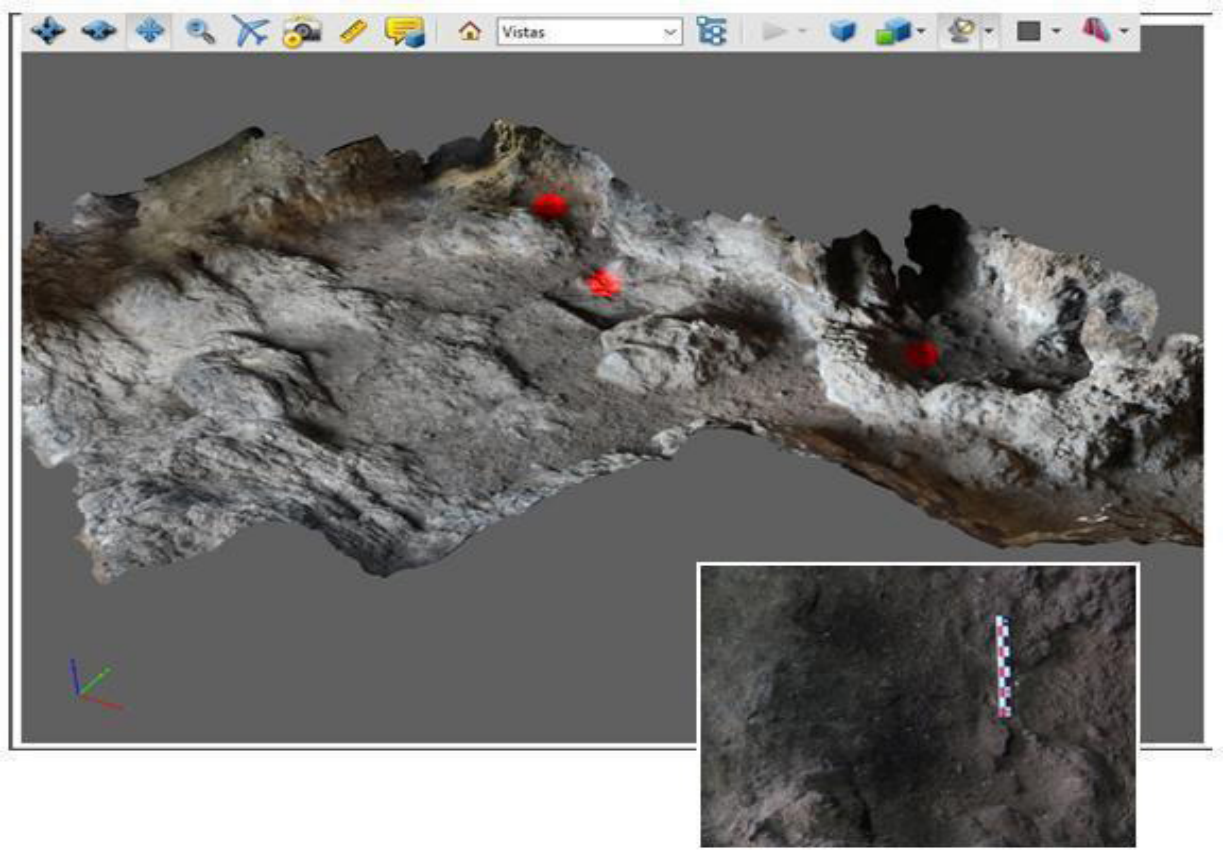

Figura 8. Superficie en 3D de la cueva 2 a partir de la técnica fotogramétrica. Áreas con evidencias de facies carbonosas marcadas en rojo. Fotografías: Autores.

Los vestigios arqueológicos hallados en el estrato 2 iban desde restos de microlascas de obsidiana, fragmentos de fauna, alto porcentaje de fragmentos de cerámicos, y en menor proporción ictiofauna. Estos aparecían en mayor proporción y menos fragmentados en aquellas zonas donde se formaban oquedades naturales o adosadas a la pared de la cueva. Así ocurrió con algunos de los punzones elaborados en hueso localizados, bien conservados a pesar del nivel de afección del sedimento en el que se encontraban.

Esta unidad estratigráfica presentaba un comportamiento sedimentario bastante uniforme en todo el suelo de la cueva, salvo por la diferencia en cuanto a la proporción de clastos comentada anteriormente como a la tonalidad, siendo el sedimento más próximo a la pared de una coloración marrón oscura. Mientras que el de la zona exterior tenía una tonalidad más clara, aspecto que podría atribuirse a la propia humedad del interior de la cueva que presenta en la actualidad. ${ }^{7}$

7 Durante los trabajos de excavación se tomaron valores de humedad y temperaturas máximas y mínimas para el último trimestre del año 2018. Aunque estos datos hay que tomarlos y analizarlos en su justa medida y un contexto bastante diferente al que pudo existir en el pasado. Los datos obtenidos en la pared de la cavidad 2 fueron de max. $22^{\circ}$ y $88 \%$ humedad, min. $17^{\circ}$ y $56 \%$ humedad. Las filtraciones que pudimos observar durante la ejecución de esta fase de trabajos en la mayoría de los casos tuvieron lugar en la cavidad 1 y en el acceso principal. Por el contrario, la única filtración de agua que tuvo 


\subsection{Las huellas parietales}

Uno de los resultados más interesantes obtenidos tras la intervención arqueológica en las cuevas de Bencomo fueron las diversas huellas parietales que aparecieron, como ya hemos comentado, especialmente en la entrada de la primera cavidad. Durante las labores de limpieza del acceso en la segunda fase de la intervención y, tras un mayor y exhaustivo análisis macroscópico de las paredes y suelos, se pudo localizar un hueco relleno con sedimentación con puntos de carbonatos (Figura 9). Este correspondía a una oquedad perfectamente circular y realizada en el suelo, en el lado derecho del acceso principal de la cueva 1 . Sus dimensiones, unos $5 \mathrm{~cm}$ de diámetro, y su posición de manera perpendicular a otra oquedad localizada en el techo de tendencia más oval y perforada intencionalmente, le confiere una verticalidad en el margen derecho del acceso muy semejante a un eje giratorio de una mampara o puerta de sellado.

De esta manera, se comprueba que las cazoletas que se registraron en la primera fase de intervención no todas corresponden a goznes de un posible cierre, estando las huellas del suelo relacionadas con un sistema de canalización de líquido hacia el exterior de la cueva 1.

La existencia de huecos para establecer una guía en el lado derecho del acceso principal de las cavidades de Bencomo es un hecho, ahora bien, en qué momento se llevó a cabo el cierre de estas cuevas; se sella cuando cambia la funcionalidad de esta o cuándo cambia de propietarios; y qué querían sellar en su interior; son algunas de las cuestiones que plantea una evidencia tan singular en estas cuevas de origen guanche.

Varios estudios indican que la existencia, uso y la práctica de excavar y acondicionar cuevas de manera artificial se conoce desde 1497 en la isla de Tenerife y que estarían relacionadas de manera directa o indirecta con población aborigen proveniente de Gran Canaria, que recibieron tierras y propiedades tras participar en la conquista de la isla de Tenerife (SERRA, 1978; BETANCOR, 1998; LARRAZ, 1998; Mederos et al., 2004).

En las datas, particularmente en los repartimientos hechos a los aborígenes canarios, se hace mención a la existencia de cuevas horadadas que irían desde Güímar hasta el Valle de Taoro. Si bien no es hasta 1507 cuando se nombra por primera vez para La Orotava la existencia de cuevas horadadas (SERRA,1978: data 447-24). Por tanto, podríamos entender que las cavidades horadadas citadas para La Orotava tendrían su morfología de acceso trabajada en una fecha anterior a 1507, pero no podemos determinar desde qué momento. Además, según apunta A. LARRAZ (1998), en el propio repartimiento de tierras y cuevas los solicitantes ya hacían uso o transformación de esos bienes antes de la concesión de la data.

lugar en la cavidad 2 provenía de la escorrentía del espacio definido en la primera fase como cavidad 3 , y que actuaría de rampa de descenso. Este hecho, unido al hallazgo de evidencias en el acceso de la cueva 1 nos hace replantearnos la función que pudieron tener las cazoletas y canales documentados en el suelo del acceso a las cuevas. 

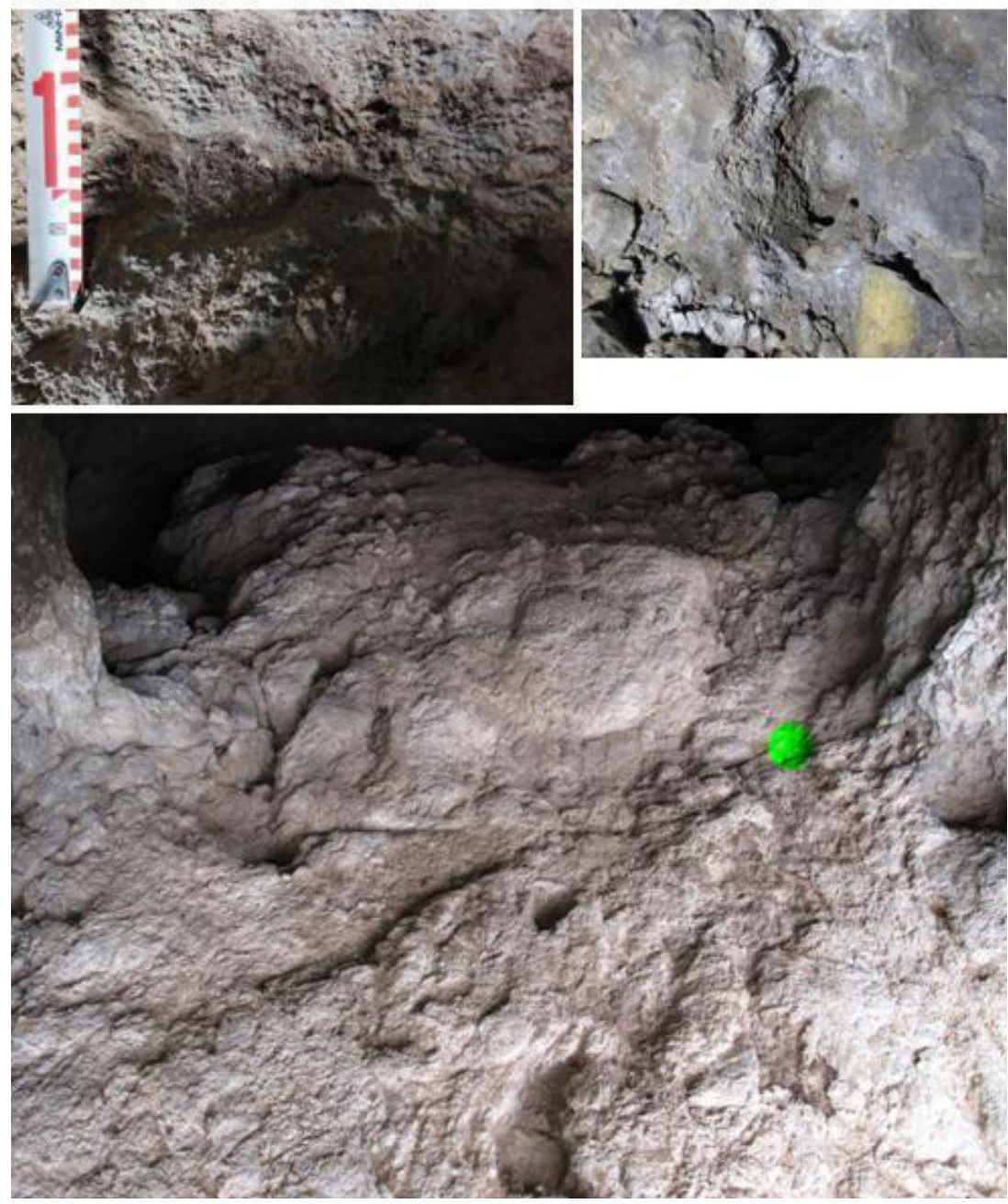

Figura 9. Hueco de gozne relleno de sedimentación, en el lado derecho del acceso, imagen superior izquierda. La imagen de la derecha corresponde con el hueco trabajado en el techo en la posición perpendicular y opuesto al anterior. Fotografía: Autores.

\subsection{El registro estratigráfico}

Durante el proceso de excavación de las cuevas de Bencomo, se verificaron los parámetros estratigráficos definidos en el sondeo realizado en la fase 1 (2017). En el seguimiento estratigráfico se observó que la génesis sedimentaria del depósito de la cueva tenía una mayor potencia estratigráfica hacia la pared, y que el depósito de estiércol y arena denominado como UE-1 no era más que la sedimentación formada tras el decapitado del resto de la estratigrafía. 
Esto confirma que tras los sucesivos expolios que tuvieron lugar en las cuevas, así como el uso de la sedimentación interior como recurso agrario, provocaron la pérdida de la mayoría del depósito estratigráfico con la respectiva ausencia de información arqueológica y por consiguiente histórica. Debemos de entender que este hecho eliminó los últimos suelos de ocupación guanche y que presumiblemente corresponderían con los eventos históricos relacionados con el momento de la conquista de la isla y con la Historia del Mencey Bencomo. A pesar del negativo pronóstico que recogía la documentación histórica y los informes emitidos por diversos profesionales, la evidencia de existencia de un depósito estratigráfico como reducto de suelos de ocupación guanche es una realidad innegable.

El hecho de haber sido colmatado por un depósito de estiércol, acumulado durante 200 años, ha dejado al resguardo $12 \mathrm{~cm}$ de ocupación de unas cuevas que, a pesar de su escasa entidad estratigráfica, ha aportado una información esencial para determinar qué actividades pudieron desarrollarse en este espacio y cuándo. Las evidencias que han arrojado algo de luz en cuanto a la posible funcionalidad de este suelo son variadas y van desde cuentas en arcilla hasta una gran cantidad de fragmentos cerámicos con morfología de recipientes de grandes dimensiones que servirían de almacenaje. Además, otros vestigios de diferente naturaleza se encontraban termoalterados debido a la presencia de fuego, a los que se les pudo relacionar restos de ictiofauna, fauna y dentición de ejemplares de la familia Ovica-prinae, y suidos. Esto nos informaría de unas actividades que formalmente pueden definirse como de mantenimiento o cotidianas, equiparables con funciones domésticas dentro de un espacio habitado (VeLOZ, 1986; GONZÁleZ y PicAzo, 2005; KISS, 2014; Jover, 2013).

\subsection{Dataciones radiocarbónicas}

En lo que respecta a la datación radiocarbónica, de los 120 restos faunísticos localizados, se seleccionaron dos piezas dentarias de los levantamientos 8 y 9 de UE-2. De esta manera, se enviaron al laboratorio dichas piezas de cáprido (CapraHircus) (Beta-506560_522311) y una semilla de cebada carbonizada (Barley), localizada en el depósito del levantamiento 7 de UE-2 y seleccionada por el Dr. Jacob Morales Mateo de la ULPGC (Beta-523055). 
GRÁFICO 1

Calibrado de las dataciones de la ocupación UE-2

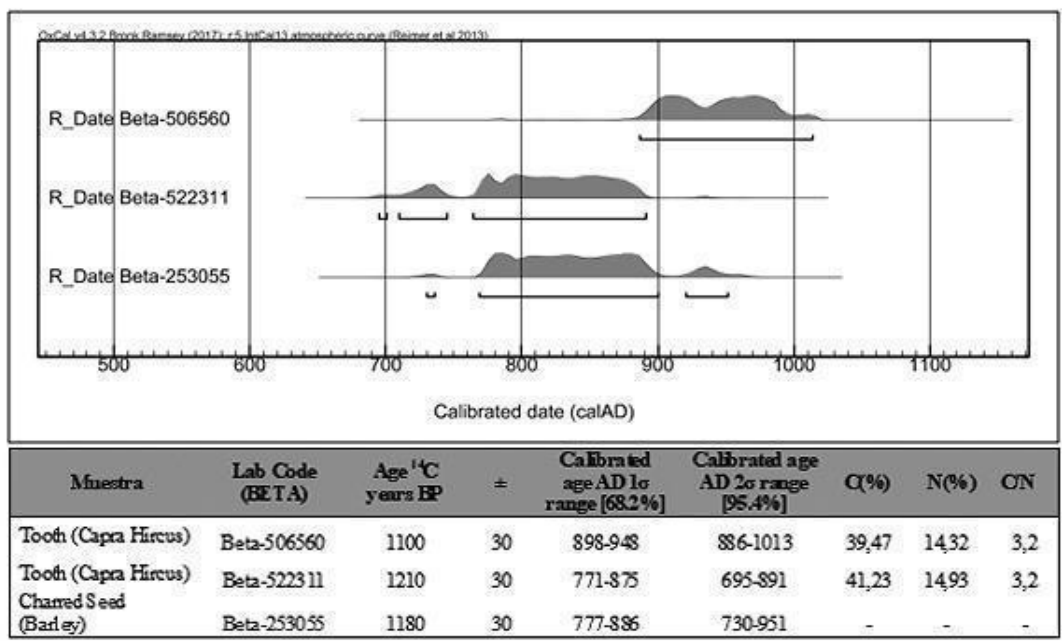

Elaboración propia.

El resultado de las muestras nos informa de que estamos ante uno de los yacimientos más antiguos registrados en intervenciones arqueológicas recientes para la isla de Tenerife. Así, la unidad estratigráfica 2 corresponde a un depósito cuyos eventos de ocupación tienen un rango temporal que va del siglo vIII al $x$ d.C. Este hecho evidencia que la realidad arqueológica conservada en el estrato es mucho más antigua que los hechos históricos que relatan las crónicas de la conquista y las datas para este importante enclave arqueológico.

\subsection{El registro material}

En las características generales del depósito del estrato 2 destaca, sobre todo, la gran cantidad de materiales arqueológicos localizados, elementos cerámicos, lascas de obsidiana y fauna. En este último caso, son relevantes las piezas de dentición de ovicápridos y suidos, un total de 32 restos en el primer caso y 21 en el segundo. Si atendemos a estas proporciones y teniendo en cuenta la presencia de recursos cárnicos de suidos, algunos investigadores relacionan esta evidencia directamente con emplazamientos más o menos estables de los lugares de habitación (AlberTo et al., 2017). En lo que respecta a los fragmentos de cerámica predomina el tipo II (ARNAY y GONZÁLEZ, 1984), y como dato significativo aparecen diversas cuentas de arcilla, tres punzones elaborados en hueso y numerosas microlascas de obsidiana. 


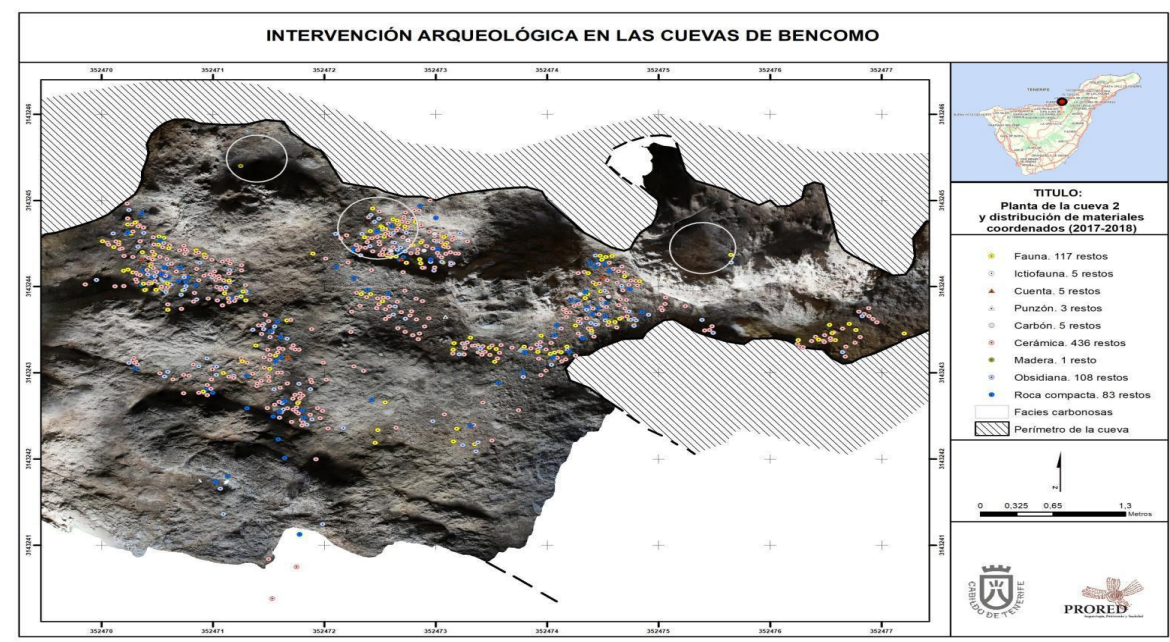

Figura 10. Distribución de materiales arqueológicos coordenados en todos los levantamientos de UE2, aplicando los principios de los SIG y el registro fotogramétrico en 3D. Elaboración propia.

Se ha coordenado un total de 763 restos arqueológicos, todos ellos pertenecientes a la UE 2. Su distribución por naturaleza se muestra en el gráfico 2. En el plano elaborado a partir de registro fotogramétrico y los SIG (Figura 10), podemos observar las concentraciones y áreas de actividad relacionadas con el evento de combustión FC1-2, adosado a la pared de la cavidad. En cuanto al registro documentado en toda la superficie, nos centraremos en analizar aquellas naturalezas con vinculación directa a actividades que nos puedan arrojar algo de información sobre el carácter doméstico o habitacional de este espacio durante el siglo IX, sin descartar la posibilidad de su uso como espacio de almacenaje.

\section{GRÁFICO 2}

Elementos coordenados en la UE-2, separados según su naturaleza

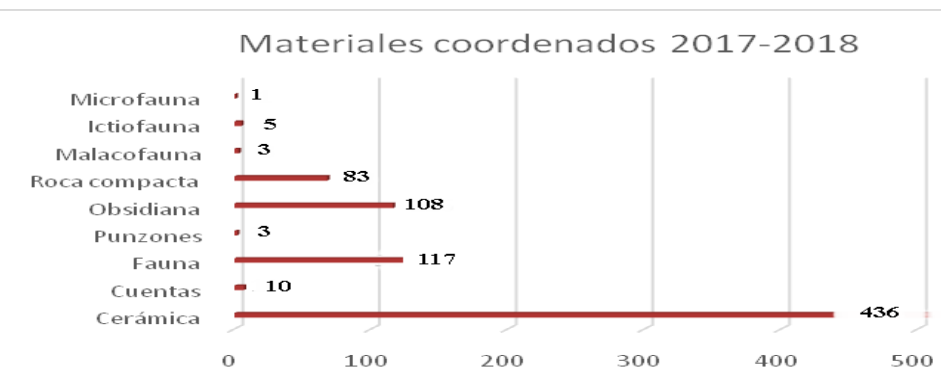

Elaboración propia. 


\subsubsection{La cerámica}

La cerámica recuperada en la cueva 2 de Bencomo es homogénea desde el punto de vista tipológico. La práctica totalidad de los restos que conservan elementos diagnósticos (apéndices y/o decoración), suman 51 piezas del total (436 elementos coordenados). Estos son adscribibles al tipo II-III, con un único caso de un asa vertical cilíndrica del tipo I.

Para realizar el estudio preliminar se seleccionaron esos 51 fragmentos, que presentaban características que permitían realizar un análisis diagnóstico de la tipología. De esta manera, se contabilizaron los apéndices, los restos con decoración y los labios, independientemente de que estuvieran decorados o no.

En el análisis tipológico se ha tenido en cuenta la clasificación realizada por ARNAy y GonZÁLEZ en 1984, la cual establece las características generales de la cerámica en tres grupos.

TABLA 1

Características de los fragmentos seleccionados para estudio

\begin{tabular}{|c|c|c|c|}
\hline $\mathbf{N}^{\mathbf{0}}$ total de fragmentos & Labios & Paredes & Apéndices \\
\hline 51 & 26 & 22 & 3 \\
\hline Decorados & En el labio & En la pared & \\
\hline 33 & 11 & 22 & \\
\hline
\end{tabular}

Elaboración propia.

En nuestro caso, hemos agrupado los tipos II y III en un mismo conjunto, puesto que la similitud de estos vasos dificulta su adscripción tipológica a partir de fragmentos. Resulta más fácil discriminar entre restos adscribibles al tipo I de los fragmentos que presentan características del tipo II-III.

Como norma general, las diferencias básicas entre estos grupos se resumen en la siguiente tabla, teniendo en cuenta la casuística presente en los restos recuperados en la cueva 2 de Bencomo:

TABLA 2

Características tipológicas de los fragmentos recuperados

\begin{tabular}{|l|l|l|}
\hline & \multicolumn{1}{|c|}{ Tipo I } & \multicolumn{1}{|c|}{ Tipo II-III } \\
\hline Decoración labio & $\begin{array}{l}\text { Incisiones/impresiones } \\
\text { profusas }\end{array}$ & $\begin{array}{l}\text { Incisiones/impresiones poco } \\
\text { profusas }\end{array}$ \\
\hline Decoración pared & Ausente & $\begin{array}{l}\text { Incisiones, acanaladuras e } \\
\text { impresiones }\end{array}$ \\
\hline
\end{tabular}


Marrero, Ruiz, García, Sossa, Abreu y Cancel

\begin{tabular}{|l|l|l|}
\hline Decoración en el labio y la pared & Ausente & Presente en muchos casos \\
\hline Asas de cinta & Ausente & Presente en los anforoides \\
\hline Protuberancia en la base & Ausente & $\begin{array}{l}\text { Presente en los anforoides y } \\
\text { vasos elipsoidales }\end{array}$ \\
\hline Apéndice tipo mamelón & Ausente & Presente en vasos esféricos \\
\hline Acabados de buena calidad & Alta proporción & Baja proporción \\
\hline Acabados de calidad mala o regular & Baja proporción & Alta proporción \\
\hline
\end{tabular}

Fuente: ARNAY y GONZÁLEZ (1984). Elaboración propia.

En cuanto a la calidad de las pastas destaca un grupo significativo de fragmentos que presentan buenos acabados e, incluso, alisado superficial tanto al interior como al exterior de las piezas, lo que contrasta con las características generales que se mencionan en la tabla anterior. Observando estos datos, estaríamos ante un conjunto cerámico adscrito al grupo II-III que sale ligeramente de la norma en cuanto a las peculiaridades de su acabado.

El estado de conservación de los restos es regular. El análisis de visu muestra un elevado número de casos que presentan erosión postdeposicional de las aristas de los fragmentos, indicando un relativo grado de movilidad después de su fractura. Aun así, ha sido posible describir los motivos decorativos y su posición dentro de la morfología de los vasos como se muestra en la tabla 3. Un inconveniente a tener en cuenta ha sido el tamaño de algunos fragmentos, puesto que un número significativo conserva el labio y poco recorrido de la pared por lo que no ha sido posible asignarle características decorativas a estos últimos. En otros casos, son fragmentos de paredes los que no conservan labio. Atendiendo a esta variable, se contabilizaron 33 fragmentos decorados, de los cuales 7 presentan decoración en el labio, 22 en la pared y 4 en el labio y la pared.

TABLA 3

Motivos decorativos presentes en 33 fragmentos de los 51 seleccionados para el estudio

\begin{tabular}{|l|c|c|c|}
\hline & $\begin{array}{c}\text { Motivos decorativos } \\
\text { en la pared }\end{array}$ & $\begin{array}{c}\text { Motivos decorativos } \\
\text { en el labio }\end{array}$ \\
\hline Incisiones & 15 & Impresiones digitales & 2 \\
\hline Acanaladuras & 10 & Impresiones no digitales & 5 \\
\hline $\begin{array}{l}\text { I m p r e s i o n e s } \\
\text { digitales }\end{array}$ & 2 & Incisiones profusas & 1 \\
\hline & & Incisiones poco profusas & 3 \\
\hline
\end{tabular}

Elaboración propia. 
En cuanto a los apéndices, se han recuperado pocos fragmentos de asas o del arranque de éstas, estando presentes en un fragmento de asa de cinta, en un mamelón, y en el asa cilíndrica vertical mencionada del grupo I.

Muchos de los aspectos formales de los fragmentos recuperados nos informan sobre vasos cerámicos de gran capacidad, entre los cuales se han reconocido algunos cuya forma y decoración son propias de «anforoides». Para el conteo de estas piezas se tuvo en cuenta aquellos fragmentos de cerámica que presentaban decoración en su pared, y cuya orientación mostraba un alto grado de verticalidad, asociado a los cuellos o paredes de ánforas. Este análisis preliminar, en el cual se descartaron aquellos motivos decorativos similares entre sí, al igual que los apéndices, debido a la alta probabilidad de que pertenecieran al mismo recipiente, dio como resultado la existencia de por lo menos 11 «anforoides» recuperados en la UE-2 de la Cueva de Bencomo.

\subsubsection{Características de la cerámica del grupo II-III de la Cueva de Bencomo}

Pertenecen a este grupo los grandes vasos $\mathrm{u}$ «anforoides» con asas de cinta. Todos ellos presentan las siguientes características comunes: las terminaciones son generalmente de calidad media y buena, las pastas asimismo de regular o buena calidad y con predominio de desgrasante medio y grueso; la forma del labio es generalmente apuntada, redondeada o plana y muchas veces sin decoración. Cuando ésta existe pueden ser impresiones puntilladas o digitadas, y alguna en impresión, pero en todos los casos la profusión es escasa. En este grupo de vasos puede aparecer decoración en la pared externa; ésta consiste principalmente en incisiones y/o acanaladuras formando motivos rectilíneos en una franja que abarca el cuello hasta el labio.
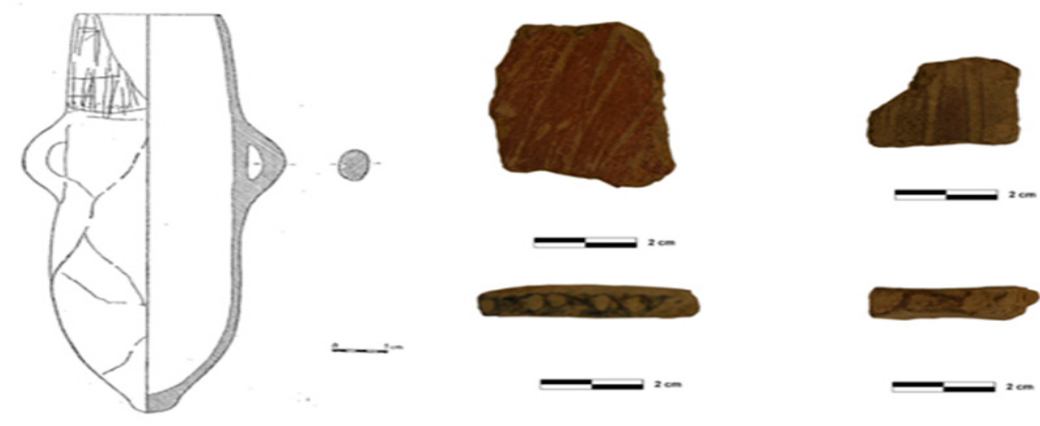

Figura 11. Elementos decorativos presentes en la cerámica recuperada en la Cueva de Bencomo. Forma interpretada a partir de los restos de la Cueva 2 Bencomo. Fuente: ARnAY y GonZÁlez (1984). 
No resulta sencillo reconocer la función principal destinada a cada una de las formas cerámicas guanches, aunque de acuerdo con algunas de ellas podemos deducir cuál fue su uso preferente a falta de análisis de los elementos que pudieran quedar adheridos en la pared interna de las piezas. Los «anforoides» y vasijas de tamaño grande pudieron servir para contener y almacenar diferentes productos sólidos como semillas, puesto que las características de las pastas (ausencia de engobe y escaso grado de vitrificación en la cocción) no permitirían el almacenamiento de líquidos a largo plazo (RHODES, 1990). En este sentido cabría señalar la presencia de una pátina o adherencia de coloración negra en el interior de algunos fragmentos que podrían estar relacionados con el uso, con la cocción de la cerámica o con la intención de impermeabilizar el recipiente (Figura 12). El análisis químico de estas pastas resultaría clarificador para esta variable (ROFFET-SALQUE et al., 2017).

En cuanto a la capacidad y dimensiones de los «anforoides» de la cueva 2 de Bencomo, ha sido imposible realizar cálculos a partir de los fragmentos. En cualquier caso, el análisis estadístico realizado para vasos con características tipológicas similares procedentes de Las Cañadas del Teide, muestra unas capacidades que superan los 20 litros y unas dimensiones superiores a los 40 $\mathrm{cm}$. Estaríamos por lo tanto ante recipientes de gran capacidad destinados al almacenado o conservación de productos que, por el momento, desconocemos su naturaleza ya que el transporte continuo de estos vasos con contenido no sería una tarea sencilla, máxime cuando el acceso a esta cavidad presenta dificultades por el tipo de terreno. Además, debemos de presuponer un contexto funcional diferente para los sitios de la alta montaña de Tenerife, donde se hallaron estos vasos cerámicos de estudios anteriores.
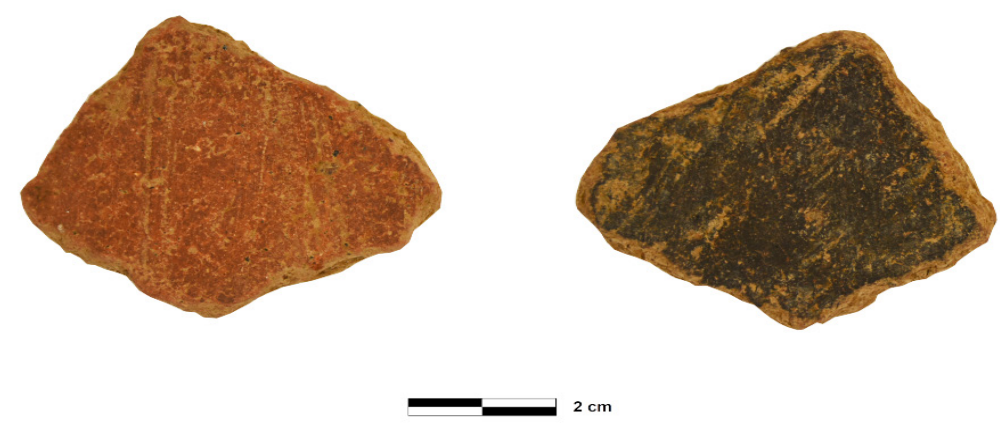

Figura 12. Fragmento de vaso cerámico «anforoide» en el que se aprecia la pátina interior ennegrecida. Fotografía: Autores.

Como se ha mencionado, la mayoría de los fragmentos cerámicos recuperados en las cuevas de Bencomo corresponden con la tipología II-III, entre los que además 
de los fragmentos antes descritos se pudieron observar fragmentos con apéndice tipo mamelón que, generalmente, suelen aparecer dobles, en vasos de forma casi exclusivamente esféricas.

Aparte de estos tipos cerámicos identificados en el registro de la cueva, se documentaron 10 cuentas de arcilla (5 coordenadas y 5 en criba), muchas de ellas enteras, presentes en diferentes formas y tamaños. Las más comunes son las que tienen forma de disco, aunque también las hay tubulares (pueden estar segmentadas), y de barril. Este tipo de objeto pudo ser utilizado tanto por hombres, como por mujeres y niños. En el momento de la muerte se incorporaban como parte del atuendo mortuorio, de ahí que sean muy frecuentes en los yacimientos de carácter funerario (NAvarro y Clavijo, 2011). No obstante, es también muy común localizar este tipo de objetos en espacios con una funcionalidad doméstica o habitacional relacionada con hogares, como se ha constatado en los últimos años en la Isla de Tenerife, y que remarcaría el uso cotidiano de estos espacios.

\section{DISCUSIÓN: EL DEBATE HISTÓRICO DE LAS CUEVAS DE BENCOMO}

La ubicación de las Cuevas de Bencomo ha producido un debate historiográfico intenso desde el siglo XVIII. La mayor parte de los documentos escritos que hacen mención a las cuevas han sido recogidos recientemente en un informe de Ramón CEBrí́n (2016). Las datas consultadas tanto por él como por otros autores (SERRA, 1974; Bello, 1990; BetANCor, 1998; LARraZ, 1998; Mederos et al., 2004, 2017; TejERA, 2016), expedidas desde 1497 y relacionadas con el repartimiento de tierras y aguas de la isla de Tenerife tras la conquista, son claves dado que en ellas se recogen topónimos guanches y localizaciones, aunque con algunas deformaciones atribuidas al desconocimiento del territorio y a errores de transcripción.

Las tres primeras datas que hacen referencia a las Cuevas de Bencomo se muestran a continuación, si bien es cierto que, como el propio Cebrián señala, es posible que en el valle de la Orotava hubiera varios lugares que usaran dicho topónimo:

613-14. «-Pedro de Madalena e Juan de Cartaya, canarios. Un pedazo de ta. de obra de 2 c. de sembradura q. están en Taoro, de s., cabe las cuevas q. llaman los guanches Taforya, cerca del auchón q. era del rey de Taoro. Más las dos cuevas de Taforya con sus corrales. Que se lo do. 15-I-1501» (SERRA, 1978: 133).

903-17. «- Pedro Delgado y Juan Dana, de la Grand Canaria. Un manantial q. resuma de una peña q. es en Tahoro arriba del auchón del Rey Grande y 7 f. de ta. de sembradura junto al dho. manantal. 22-I-1501» (SERRA, 1978: 181)

920-34. «-Lope Gallego. Unas tas. q. fueron de Lorenzo de Alcalá, de s., q. son 3 c., yendo del Ingenio q. hace agora Bartolomé Benítez hacia la montaña debajo de un pino con monyolera y unas cuevas q. están entre mis tas. e las q. fueron de Padilla el Auchón del Rey con sus entradas e salidas. 2-VII-1507» (SERRA, 1978: 184). 
Luego hay otras datas posteriores que aluden de una manera más indirecta a las posibles cuevas del Mencey Bencomo:

743-24. «-Rodrigo Fernandes. 2 c. en Taoro en el Arabtaba, linde de arriba el camino q. viene de casa del Rey Grande, e de la parte de abajo Juan Fernandes, e de la parte el Barranco Grande e de la otra parte el paso grande q será obra de 4.c. Q. se vos asiente 2 c. en dho. lugar, 6-V-1506» (SERRA, 1978: 154-155). ${ }^{8}$

648-40. «-... tengo doy en repartimiento e por vecindad a vos, Juan Beltrán, ... como pasamos de casa del Rey Benytomo, q. se llama el Aravtaba, e pasado el barranco yendo cara el Alaguna por el camino viejo..., 15-II-1508» (SERRA, 1978: 146). ${ }^{9}$

447-24. «-Toda la demasía q. hoviere en las tas. q. yo di a Diego de Cala, vuestro suegro q. h. s. g., q. son en Taoro bajo de la cuesta, junto de unos almácigos, linde donde tiene las colmenas de Antón de la Sierra e Pedro Delgado de Grand Canaria e su enterado, e de parte de arriba la cueva horadada derecho a las cuevas q. están encima de los almácigos q. están encima de las colmenas del dho. Antón de la Sierra. 11-XII-1507» (SERRA, 1978: 100).

Muchas datas que describen cuevas horadadas lo hacen como lindes territoriales o límites de tierras, además, estás datas relacionan dichas cuevas con pobladores aborígenes de Gran Canaria que participaron en la conquista de la isla de Tenerife (Mederos et al., 2004).

Para entender este yacimiento es necesario acudir a la figura del historiador portuense José Agustín Álvarez Rixo (1796-1833), cuyo trabajo supone un punto de inflexión mostrando diversas referencias a la cueva residencial del Mencey Bencomo. Para Álvarez, las cuevas de Bencomo aparecerían en la documentación sobre la conquista de Tenerife bajo el epígrafe "Tamayde» y cuya ubicación: «se hallaba situada a corta elevación de la ladera nordeste de la Orotava, a orillas del Barranco El Pinito, en la parte en que este hace un salto semicircular, formando un aprisco natural y cómodo para ganados» (TEJERA, 2016: 60).

El propio historiador portuense indica que visitó las cuevas y realizó una descripción ${ }^{10}$ de lo que él consideró que era la cueva-vivienda, el auchón del Mencey de Taoro:

Tamaide o cueva palacios, es la gruta que sirvió de habitación al virtuoso Quevehí Bencomo (...) Consta el alojamiento de dos cuevas o más bien diré tres. En la primera forma el risco una especie de pórtico irregular vuelto al sud-oeste, desde el cual agachándose un poco se pasa a la gruta, que tendrá siete varas de diámetro desigual; y cuyo techo apenas tiene el alto de un hombre regular. Del lado sur, se halla un boquerón o pasadizo de cosas de dos varas de ancho y poco más de uno de alto, que comunica con la segunda estancia, la cual tiene el techo alto y despejado, casi toda

8 Data otorgada a Rodrigo Fernández en 1506, aborigen canario.

9 Data entregada a Juan Beltrán en 1508, aborigen canario.

10 Rixo hace sugerencias de usos de materiales como el pajizo para tapar el frente descubierto del segundo habitáculo. El autor no nombra en ningún momento la presencia de útiles aborígenes. Tampoco señala que excavara la cueva en busca de algún vestigio antiguo, por lo que se entiende que no halló restos, sino que en su inspección de las cuevas se limitó a la localización de lo que la tradición popular señalaba como vivienda-habitación del monarca de Taoro. 
descubierta por el lado de poniente (...) desde esta se para por un arco a la tercera, más corta que las otras y más descubierta también. En el arco de la puerta de la cueva (...) está pintado en miniatura el valle, las cumbres y el pico. Si se sale tres varas más afuera hacia la entrada, se magnifica más la escena, pues se ve también, la costa, el batir del mar, la isla de la Palma (...). Muy cerca pero algo más alto, está una fuentecilla de buena agua, y poco más al norte otra larga gruta llamado ahora el bucio, que por tener el piso lleno de piedras caídas, cuesta encorbarse bastante para transitar a su interior que es más largo, en el cual filtra el agua del manantial (Álvarez, 2005 [1839]: 166-168).

Álvarez (2005 [1839]:168) remata su texto de descripción de la cavidad con las siguientes palabras:

Solo se encuentra escrita con giz (pasta hecha con yeso), en el techo de la primera gruta la siguiente inscripción: Aquí habitó Quevehí Bencomo, Mencey de Taoro, virtuoso defensor de su Paytria, de la cual y de la libertad le privó la codicia de los Españoles en 1497.Una cuestión que es necesario señalar con relación a estas cuevas es la existencia de agua en el entorno de la vivienda, y que muy cerca, pero algo más alto, hay una fuentecilla de buena agua, y poco más al norte otra larga gruta llamada ahora el bucio, que por tener el piso lleno de piedras caídas, cuesta encorvarse bastante para transitar a su interior que es más largo en el cual se filtra el agua del manantial, estando esta fuente a apenas a 50 metros de distancia de la cueva.

En este trabajo presentó una serie de argumentos para relacionar la cueva de Tamayde con la descripción del auchón del Rey Grande en Taoro, como aparece desde muy pronto en la documentación del siglo XVI. El nombre de auchón parece referirse a una cueva-vivienda que a su vez tendría funciones de almacenaje de varios recursos posibles, grano, colmenas, e incluso como redil o corral para el ganado.

No obstante, esta definición no ha sido aceptada de forma unánime. A partir de la tradición oral del siglo XIX, Bethencourt Afonso plantea en una nota que se trataría de una finca o medianería que incluía también casitas, chozas y cuevas, unidad territorial cada 3 o $4 \mathrm{~km}^{2}$. Para Martínez de la Peña, corresponde a un lugar con cuevas que servían para guardar ganado o almacenar grano, queso, pieles o manteca. EsPINOSA y MOAS (1992: 3-5) señalan algunas de sus características:

Algunos estaban en cuevas, que eran habitables o sirvieron para encerrar el ganado o madera, pero no eran cuevas, pero ni tampoco estructuras fijas porque podían estar sólo, pasajeramente en un sitio como indica una data de Agüimar de $1516 .{ }^{11}$

Finalmente, según Mederos y Escribano (2017) se trataría de un espacio agrícola cultivado, con alguna cueva grande aneja que podía servir de lugar de almacenaje. En la historiografía sobre estudios de los modos de vida guanche siempre ha existido una tendencia a identificar la cueva como vivienda, lugar donde se realizan la totalidad de las actividades cotidianas de quienes la habitan:

11 «Es una foya con unas cañadas, donde solía estar un auchón en tiempo de los guanches» (SERRA, 1978: 318). 
preparación de alimentos, fabricación de herramientas, etc. Sin embargo, para el caso que nos ocupa, podríamos estar ante un nuevo tipo de yacimiento que hasta ahora no había sido evidenciado en los trabajos arqueológicos de la isla. El hábitat en cueva, en el periodo guanche, era común sobre todo en el norte de la isla debido a las condiciones geológicas y de habitabilidad. En principio, el condicionamiento de las mismas consistía en la nivelación y preparación del suelo, adaptando muros de cierre en el exterior o colocando mamparas de material efímero, sostenidas por soportes de madera (CUSCOY, 2008; LARRAZ, 1998). Pero esta visión, sesga otra realidad diferente para los modelos de ocupación y asentamientos de la isla, mucho más compleja en cuanto a las formas de hábitat y maneras de ocupar el territorio. Una de las causas es el propio devenir histórico del territorio tras la conquista castellana, puesto que el intenso proceso de roturación tras el repartimiento de tierras para la producción agrícola afectaría a la conservación de los conjuntos habitacionales, sobre todo, a las estructuras de superficie y cabañas (Hernández MARrero, 2006).

En los primeros años tras la conquista, era común que los colonos hicieran uso de casas-cuevas, muchas de ellas en zonas alejadas de los núcleos de población más grandes (BETANCOR, 1998). Además, existía tradición de uso de cavidades por parte no sólo de colonos de otras islas, como Gran Canaria, sino también de zonas de la península ibérica (López, 1990; Piedecausa, 2009).

Son numerosas las referencias a aborígenes canarios en las datas y protocolos notariales, como mínimo 30 canarios reciben tierras con cuevas durante la primera mitad del siglo XVI. La zona principal donde se asientan coincide con los bandos de guerra de la conquista, entre Acentejo y Los Realejos. De esta manera, el sentido de la pertenencia a este tipo de bien varía, ya que las cuevas dejan de ser propiedad del Mencey o de una misma unidad político-territorial como puede ser el menceyato de Taoro, para pasar a ser propiedad individual de aborígenes canarios, asentándose cerca de la figura del Adelantado y de otros mandatarios canarios y sus tierras (BETANCOR, 1998). Además, la apropiación de los invasores de espacios con un especial significado en la cultura guanche, en concreto de cuevas de carácter doméstico pertenecientes a personajes relevantes, se utilizaron como hecho desarticulador de la sociedad aborigen (Hernández MARrero, 2006). Según alguna data, la práctica más común para seguir viviendo en cuevas era la de mejorar el muro de su entrada, haciéndolos de mayores dimensiones, e introduciendo en ocasiones la madera para el cierre. También, en las datas, se hace referencia a cuevas horadadas como lindes de propiedad agrícola o como referencia de límites territoriales mayores, siendo las mejores aquellas con recursos hídricos cercanos, como es el caso que nos ocupa.

Una de las evidencias confirmadas tras esta intervención es que efectivamente estamos ante las cuevas que la historiografía recoge como las cuevas del Mencey Bencomo, siendo Álvarez uno de los investigadores que dejaron su huella. No sólo verificado por el grafiti en el techo de la primera cavidad, si no por la descripción detallada que hace de su interior y por la muestra pictórica del vano de acceso. La posibilidad de existir una mampara que cubriría la ventana de visión hacia el valle de la Orotava en la cavidad 2, se hace patente con la identificación de 
las huellas parietales a ambos lados de la propia ventana que se abre al caboco, estando posiblemente sellada en el siglo xIX como bien reflejó el cronista portuense. Esta realidad quizás podamos extrapolarla a siglos anteriores y más, si atendemos a los apuntes de historiadores como A. Larraz, indicando que es muy posible que las modificaciones que se han hecho en las cuevas se produjeran desde el repartimiento de tierras tras la conquista.

La posibilidad de que las evidencias del trabajo de horadado para el sellado de las cuevas sean anteriores al momento de la conquista, aunque mínima, puede ser factible para una sociedad guanche que conocía el trabajo de la piedra volcánica, tanto de la toba en las regiones del sur de la isla, (reflejado en manifestaciones como las estaciones de cazoletas o canales), como por su amplio registro sobre el trabajo de la talla de otras materias duras como el basalto compacto o vacuolar. Para Larraz, siguiendo a Serra y extrayendo sus propias conclusiones de la lectura de las datas, un auchón sería una: «Cueva labrada, adaptada artificialmente, acaso una verdadera construcción en la cual tiene parte importante la madera» (SERRA, 1978:12-13).

De confirmarse este planteamiento, sería la primera vez que en el norte de Tenerife se documenta un recinto que ha sido transformado en época guanche para añadirle un elemento a modo de puerta para sellar un espacio, tal y como ocurría con casas y graneros en Gran Canaria. El uso como almacén de recursos en estas cuevas, para los siglos VIII-X, no queda descartado con esta intervención, aunque la presencia de fuego y restos faunísticos señalan un uso doméstico o culinario. A pesar de la polémica con el término auchón, en el siglo XV-XVI debió de ser un espacio de grandes dimensiones, al resguardo de las inclemencias, donde poder guardar ganado, grano, $\mathrm{u}$ otros recursos secundarios y ser utilizado a su vez como vivienda, donde el acceso a un bien tan preciado como el agua estaba asegurado. Independientemente de su morfología física, por su propia naturaleza se le presupone un sistema de cierre o protección y delimitación, sea redil o vivienda, o zona de almacenaje, puesto que debía de ser distinguible en el territorio incluso, (en el caso de que fueran cuevas), para diferenciarlas de las demás, tal y como apunta Larraz(1998: 238). Si atendemos a esto, podríamos presuponer que el sistema de cierre es anterior al repartimiento de tierras a población canaria y por lo tanto las cuevas estarían selladas. Ahora bien, la necesidad de sellar un auchón es debido a la naturaleza de la propiedad de los bienes que se encuentran en su interior o por la propia naturaleza del bien en sí (ganado).

\section{CONCLUSIONES}

Con la ejecución de este proyecto, el análisis parcial de sus resultados y la obtención de tres dataciones absolutas con un rango temporal entre los siglos VIII-X, podemos afirmar que el registro sedimentario y los suelos arqueológicos que aún conservaba la cueva $\mathrm{n}^{\circ} 2$ nada tienen que ver con el yacimiento tal y como lo pudo conocer el Mencey Bencomo. La realidad arqueológica a la que hemos 
podido acceder evidencia que a pesar de las desavenencias y afecciones que pueda tener un bien patrimonial siempre se puede obtener información valiosa si se realiza un trabajo exhaustivo y minucioso, a la vez que multidisciplinar. Los datos aportados con la intervención generan nuevas preguntas sobre los posibles usos que tuvo la cueva de Bencomo durante el siglo Ix, funcionalidad que con toda probabilidad haya cambiado a lo largo de los siglos hasta los últimos decenios del Menceyato de Taoro. Las evidencias arqueológicas, a pesar de los expolios, nos hablan de un lugar con numerosos fragmentos cerámicos procedentes de vasos de gran capacidad, pero también de piezas dentarias de suidos y ovicápridos sin estar asociados a huesos de cráneos, indicios quizás, de que la matanza de los especímenes tiene lugar en el mismo sitio donde se consumen y procesan (AlBERTO, 2004). Las cuentas en arcilla, los punzones, los restos de ictiofauna y las evidencias desdibujadas de hogueras nos estarían informando de una función aparentemente doméstica. Hay huellas de la transformación de alimentos, pero no podemos categorizar si esto obedece a una práctica doméstica sensu estricto o ya se empiezan a evidenciar en este momento (s. Ix) unas transformaciones de carácter social y económico que dan origen a un espacio con dualidad funcional, como es el caso de los auchones. Es decir, podríamos estar ante un modelo de espacio de procesado/conservación de alimentos cárnicos y/o almacenamiento de excedentes en recipientes cerámicos en un momento en el que la sociedad guanche, cuyo modelo de organización social que parece corresponder con un sistema tribal, comienza a complejizarse hasta los niveles del orden de los menceyatos (Tejera, 1992; Galván et al., 1999; Velasco et al., 1999; Hernández et al., 2006, Chávez et al., 2007; BAucells, 2014; MesA, 2017). Por lo tanto, aunque para el siglo Ix estemos ante evidencias de uso doméstico de las cuevas, la propiedad de la misma y de los recursos que contuvo en su interior durante el siglo xv bien pudieron pertenecer al Mencey Bencomo, tal y como lo describen algunas datas. Sin embargo, somos conscientes de que sin evidencias de los suelos del siglo XV y el decapitado del resto de la estratigrafía, las dificultades que existen para concretar y definir el registro arqueológico en áreas de actividad y, especialmente, en unidades domésticas de la cultura guanche como puede ser este caso tan particular, se convierten en una tarea compleja. No obstante, aunque las relaciones temporales sean distantes $\mathrm{y}$, las unidades de análisis espacial que puedan inferirse estén desdibujadas por el propio devenir del yacimiento y los procesos postdeposicionales, (por la reutilización y superposición en la organización de las actividades tanto en los suelos de ocupación como en el acondicionamiento de las paredes y accesos de las cavidades), estas junto con el estudio de las evidencias materiales en su contexto, se convierten en la base para analizar los posibles cambios diacrónicos en el modelo socio-económico de la cultura guanche. 


\section{AGRADECIMIENTOS}

El presente proyecto ha sido financiado por el Cabildo Insular de Tenerife P-3800001-D durante los años 2017-2018. Agradecemos a la empresa Copoc, del término municipal de La Orotava, por su colaboración. También agradecer las labores de calibración de las dataciones al investigador predoctoral, miembro del grupo de investigación de la ULL, BAPADNA, Elías Sánchez Cañadillas, y al Dr. Jacob Bentejuí Morales Mateos de la Universidad de Las Palmas de Gran Canaria por la identificación de las semillas.

\section{REFERENCIAS}

Álamo Torres, Mª.C.; CANCEl, S. (2019): «Las aportaciones innovadoras del arqueólogo Fernando Álamo Torres», Revista BIC, 2: 6-49.

Alberto Barroso, V. (2004): «De carne y hueso: la ganadería en época prehispánica», El Pajar: Cuaderno de Etnografía Canaria,18: 4-8.

Alberto, V.; Moreno, M.; Alamón, M.; Suárez, I.; Mendoza, F. (2017): «Estudio zooarqueológico de la Restinga (Gran Canaria, España). Datos para la definición de un modelo productivo», en F. Morales (coord.), Actas del XXII Coloquio de Historia Canario-Americana, Cabildo Insular de Gran Canaria, Las Palmas de Gran Canaria: 1-17.

Álvarez Delgado, J. (1947): «Cuevas de Tenerife. Cuevas de Bencomo (Orotava, Tenerife)», en Excavaciones arqueológicas en Tenerife (Canarias). Plan Nacional 1944-1945. Informes y Memorias, 14, Comisaría General de Excavaciones Arqueológicas, Madrid: 30-31.

Arnay, M.; GonZÁLEZ, E. (1984): «Vasos cerámicos prehispánicos de Tenerife. Un estudio estadístico», Anuario de Estudios Atlánticos, 30: 79-107.

Baucells Mesa, S. (2014): «El Pleito de los Naturales y la asimilación guanche: de la identidad étnica a la identidad de clase», Revista de Historia Canaria, 196: 139-159.

Bello León, J.M. (1990): «El reparto de tierras en Tenerife tras la conquista: el ejemplo del Valle de La Orotava», Historia, Instituciones, Documentos, 17: 1-30.

BETANCOR, G. (1998): «Grancanarios en el repartimiento de Tenerife en el siglo XVI», en F. Morales (coord..), Actas del XIII Coloquio de Historia de Canario-Americana, Cabildo Insular de Gran Canaria, Las Palmas de Gran Canaria: 2228-2243.

BRONK RAMSEY, C., (2017): «Methods for summaris in gradio carbon data sets», Radiocarbon, 59: 1809-1833.

Chávez, E.; Pérez, F.; Pérez, E.; Soler, J.; GoñI, A.; TejerA, A. (2007): «Propuesta de categorización arqueológica de los yacimientos aborígenes de la comarca isorana (Tenerife). La historia en activo», en R. GonZÁlez ZalacAín (coord.) Actas de las I Jornadas «Prebendado Pacheco» de investigación histórica, Concejalía de Educación y Cultura, Ayuntamiento de Tegueste, La Laguna-Tenerife: 1130 . 
Espinosa de Los Monteros, E.; Moas, E. (1992): «Ar Tahore», Ycoden, 2: 81-92.

Galván, B.; Hernández, C.; Velasco, J.; Alberto, V.; Borges, E.; Larraz, A. (1999): Orígenes de Buenavista del Norte. De los primeros pobladores a los inicios de la colonización europea, Ayuntamiento de Buenavista del Norte, Buenavista del Norte.

GonZÁlez, P.; PicAZo, M. (2005): «Arqueología de la vida cotidiana», en M. SÁNCHEZ (ed.), Arqueología y género, Universidad de Granada, Granada: 141-158.

Hernández, C.M.; Alberto, V. (2006): «Buscando la comunidad local. Espacios para la vida y la muerte en la prehistoria de Tenerife», El pajar: cuaderno de Etnografia Canaria, 21: 22-31.

Hernández Marrero, J.C. (2006): «El nuevo poblamiento. Los repartimientos en el Macizo de Anaga (1497-1525)», en U. MARTín (coord.), Historia general de la comarca de Anaga, Ediciones Idea, Santa Cruz de Tenerife: 51-91.

Jover MAestre, F.J. (2013): «Las áreas de actividad y las unidades domésticas como unidades de observación de lo social: de las sociedades cazadoras-recolectoras a las agricultoras en el este de la Península Ibérica», en S. Gutiérrez e I. Grau (eds.), De la Estructura Doméstica al Espacio Social. Lecturas arqueológicas del uso social del espacio. Serie Arqueología, Universidad de Alicante, Alicante: 13-38.

KIss, D.M. (2013): «Una visión del espacio desde la arquitectura. Tres formas de comprender las dimensiones del espacio doméstico», en S. GutiérRez e I. Grau (eds.), De la Estructura Doméstica al Espacio Social. Lecturas arqueológicas del uso social del espacio. Serie Arqueología, Universidad de Alicante, Alicante: 341-360.

LARraz Mora, A. (1998): «El uso de las cuevas y auchones como vivienda en los inicios de la repoblación de Tenerife (1497-1526)», El Museo Canario, 53: 215241.

Marrero, E.; Hernández, C.M.; Galván, B. (2011): «El análisis espacial en el estudio de las secuencias de facies arqueosedimentarias. Criterios para identificar eventos de ocupación en yacimientos del Paleolítico Medio: El Salt y El Abric del Pastor (Alcoy, Alicante, España)», Recerques del Museo de Alcoy, 20: 7- 32.

Marrero, E.; Navarro J.F.; García, J.C.; Abreu, I.; Pou, S.; Álvarez, N. (2016): «La alternancia ocupacional en la cueva de Belmaco, La Palma. Una revisión arqueosedimentaria», en F. Morales (coord..) Actas del XI Coloquio de Historia Canario-Americana, Cabildo Insular de Gran Canaria, Las Palmas de Gran Canaria: 1-19.

Mederos, A.; Escribano, G. (2004): «Hábitat aborigen en cuevas artificiales del sur de Tenerife (Arico-Granadilla)», Anuario de Estudios Atlánticos, 50: 731-780.

Mederos, A.; Escribano, G. (2017): «Los límites del menceyato de Taoro (Tenerife, Islas Canarias) y el emplazamiento de las cuevas del Mencey», Anuario de Estudios Atlánticos, 63: 1-43.

MEsa Hernández, E.M. (2017): Entre lapas y burgados. Los guanches y el aprovechamiento de los recursos marisqueros, Premio de investigación Agustín de Betancourt, Fundación CajaCanarias, Santa Cruz de Tenerife.

MillaRD, A.R. (2014): "Conventions for reporting radiocarbon determinations», Radiocarbon, 56: 555-559. 
Morales, J.; Rodríguez, A.C.; Henríquez, P. (2017): «Agricultura y recolección vegetal en la arqueología prehispánica de las Islas Canarias (s. III-XV d.C.): la contribución de los estudios carpológicos», en J. FERNÁNDEZ et al. (eds.), Miscelánea en homenaje a Lydia Zapata Peña (1965-2015), Universidad el País Vasco, Vitoria: 189-218.

Navarro, J.F.; Clavijo, M.A. (2011): 44 años de arqueología canaria. Textos escogidos de Luis Diego Cuscoy, Instituto de Estudios Canarios, La Laguna.

Piedecausa García, B. (2009): «La vivienda enterrada: estudio de su evolución tipológica y adaptación geográfica», Investigaciones Geográficas, 50: 169-189.

REIMER, P.J.; BARD, E.; BAYLISS, A.; BECK, J.W. (2013): «Intcal13 and marine13 radiocarbon age calibration curves 0-50,000 years cal BP», Radiocarbon, 55 (4):1869-1887.

RHODES, D. (1990): Arcilla y vidriado para el ceramista, CEAC, Barcelona.

SERRA RÁfols, E. (1978): Las Datas de Tenerife. Libro I a IV de datas originales, Fontes Rerum Canariarum, 12, Instituto de Estudios Canarios, La Laguna.

StuIVer, M.; PolaCH, H. (1977): «Discussion reporting of 14C data», Radiocarbon, 19, 3: 355-363.

Tejera Gaspar, A. (1992): Tenerife y los guanches. Prehistoria de Canarias, Centro de la cultura popular de Canaria, La Laguna-Tenerife.

Tejera Gaspar, A. (2016): «La cueva del Mencey Bencomo de Taoro, según Álvarez Rixo» en P. FERNÁNDEZ (coord.) Álvarez Rixo: escribir para no olvidar. Exposición bibliográfica y documental. Serie Textos 16, Universidad de La Laguna, La Laguna-Tenerife: 55-66.

VALLVERDú POCH, J. (2002): «Micromorfología de las facies sedimentarias de la Sierra de Atapuerca y del Nivel J del Abric Romaní implicaciones geoarqueológicas y paleoetnográficas». Tesis Doctoral. Universitat Rovira i Virgili.

Velasco Vázquez, J.; Hernández Gómez, C.M.; Alberto Barroso, V. (1999): «Consideraciones en torno a los sistemas productivos de las sociedades prehistóricas canarias: los modelos de Tenerife y Gran Canaria», Vegueta, 4: 33-56.

Veloz Maggiolo, M. (1986): «La arqueología de la vida cotidiana: matices, historia y diferencias», Boletín de Antropología Americana, 10: 5-22.

Vidal Matutano, P.; Morales Mateo, J.; Henríquez-Valido, P.; Marchante Ortega, A.; Moreno Benítez, M.A.; Rodríguez Rodríguez, A.C.: (2020): «El uso de la madera en espacios de almacenamiento colectivos: análisis xilológico y antracológico de los silos prehispánicos (ca. 500-1500 d.C.) de la Fortaleza (Santa Lucia de Tirajana, Gran Canaria)», Vegueta, 20: 469-489. 